doi:10.1016/j.fct.2006.07.004

Copyright (c) 2006 ILSI Europe Published by Elsevier Ltd.

\title{
Approaches to the risk assessment of genotoxic carcinogens in food: A critical appraisal
}

\section{J. O'Briena, A.G. Renwick', A. Conctablec, E. Dybing ${ }^{\text {d }}$, D.J.G. Müller ${ }^{\mathrm{e}}$, J. Schlatter ${ }^{\mathrm{f}}$, W. Slob ${ }^{\mathrm{g}}$, W. Tueting ${ }^{\text {h, }}{ }^{4},{ }^{4}$, J. van Benthem ${ }^{\mathrm{g}}$, G.M. Williams and A. Wolfreys $s^{j, 1}$}

${ }^{\text {a } F o o d ~ S a f e t y ~ A u t h o r i t y ~ o f ~ I r e l a n d, ~ A b b e y ~ C o u r t, ~ L o w e r ~ A b b e y ~ S t r e e t, ~ D u b l i n ~ 1, ~}$ Ireland

bUniversity of Southampton, School of Medicine, Biomedical Sciences Building, Bassett Crescent East, S016 7PX Southampton, United Kingdom

${ }^{\mathrm{c}}$ Nestlé UK Ltd, Food Safety/Quality and Safety Assurance Department, St

Georges House, Park Lane, CR9 1NR Croydon, United Kingdom

${ }^{\mathrm{d}}$ Norwegian Institute of Public Health, Division of Environmental Medicine, P.O. Box 4404, Nydalen, 0403 Oslo, Norway

eProcter \& Gamble Service GmbH, Sulzbacher Str. 40, 65824 Schwalbach am

Taunus, Germany

fSwiss Federal Office of Public Health, Food Toxicology Section, Stauffacherstr. 101, 8004 Zurich, Switzerland

${ }^{9}$ National Institute of Public Health and the Environment (RIVM), P.O. Box 1, 3720

BA Bilthoven, Netherlands

hInternational Life Sciences Institute, European Branch (ILSI Europe), Avenue E.

Mounier 83/box 6, 1200 Brussels, Belgium

'New York Medical College, Department of Pathology, Basic Science Building, Room 413, Valhalla, NY 10595, USA

jUnilever, Safety and Environmental Assurance Centre, Sharnbrook, Bedford

MK44 1LQ, United Kingdom

Received 26 June 2006; accepted 10 July 2006. Available online 14 July 2006.

\section{Abstract}

The present paper examines the particular difficulties presented by low levels of food-borne DNA-reactive genotoxic carcinogens, some of which may be difficult to eliminate completely from the diet, and proposes a structured approach for the evaluation of such compounds. While the ALARA approach is widely applicable to all substances in food that are both carcinogenic and genotoxic, it does not take carcinogenic potency into account and, therefore, does not permit prioritisation based on potential risk or concern.

In the absence of carcinogenicity dose-response data, an assessment based on comparison with an appropriate threshold of toxicological concern may be possible. When carcinogenicity data from animal bioassays are available, a useful analysis is achieved by the calculation of margins of exposure (MOEs), which can be used to compare animal potency data with human exposure scenarios. Two reference points on the dose-response relationship that can be used for MOE calculation were examined; the T25 value, which is derived from linear extrapolation, and the BMDL10, which is derived from mathematical modelling of the dose-response data. The above approaches were applied to selected foodborne genotoxic carcinogens. The proposed approach is applicable to all 
substances in food that are DNA-reactive genotoxic carcinogens and enables the formulation of appropriate semi-quantitative advice to risk managers.

Keywords: Carcinogens; Genotoxic; Food safety; Margin of exposure; Risk assessment

\section{Background and objectives}

Compounds that are both carcinogenic and genotoxic frequently give rise to difficulties for regulators and food businesses when they are present at low levels in foods. Among regulatory and advisory bodies, such as JECFA, EFSA and FDA, there is no international consensus on how to evaluate the potential risk of genotoxic carcinogens in food. In Europe, the Scientific Committee on Food (SCF) has addressed the topic of chemicals that may be genotoxic carcinogens in a written opinion $(\mathrm{SCF}, 1996){ }^{2}$ The SCF has evaluated genotoxic carcinogens in the diet (such as contaminants and natural toxicants) on a case-by-case basis using a "weight of evidence" approach, whereas in the USA (e.g. US EPA), as well as in some European countries (e.g. Norway), a quantitative risk characterisation is commonly performed by mathematical low-dose extrapolation of animal data. There is a vast literature on scientific and legal principles dealing with chemical hazard characterisation and this literature is not reviewed in the present publication.

It is recognised that current risk analysis approaches to compounds in food that are genotoxic and carcinogenic in experimental animals may sometimes incur disproportionate or even unnecessary measures on the part of regulators and industry. The current ILSI Europe expert group was convened in 2002 with the following objectives: (1) to propose a structured approach for the evaluation of genotoxic carcinogens in food following a critical review of the approaches currently available; and (2) to evaluate the margin of exposure approach for food-borne substances that are genotoxic and carcinogenic. An additional objective was to review the methods available for the evaluation of genotoxicity (see Supplementary data, below). The risk assessment of genotoxic carcinogens has been considered recently by the European Food Safety Authority (EFSA) and by the WHO/FAO Joint Expert Committee of Food Additives (JECFA). In 2003, EFSA established a Working Group to consider how to improve advice given on the health risks arising from the presence in food of compounds that are both genotoxic and carcinogenic. This activity led to the publication of an Opinion of the Scientific Committee in 2005 (EFSA, 2005). In February 2005 there was a meeting of JECFA, which evaluated a number of genotoxic carcinogens, with the Report published after the meeting (JECFA, 2005). Thus the current activity coincided with other efforts to address the difficult issue of providing scientifically supportable advice to risk managers about the presence of food-borne genotoxic carcinogens. These activities led to an international conference in November 2005 that involved all three groups (WHO, EFSA, ILSI Europe) (Barlow et al., 2006).

Historically, it has been assumed theoretically possible that a single molecule of a carcinogen could cause a mutation and consequently could lead to cancer. However, carcinogenesis is a multi-step process (see Fig. 1) that can be affected by chemicals in a number of ways. A carcinogen, broadly defined, is an agent that increases the occurrence of neoplasms in either experiential animals or humans (Williams and Iatropoulos, 2001). Carcinogens can be categorised as genotoxic, i.e. those that affect DNA (and can be either DNA-reactive or DNA-non-reactive), or non-genotoxic (epigenetic), according to various criteria (Williams, 1992 and Williams and Iatropoulos, 2001). 


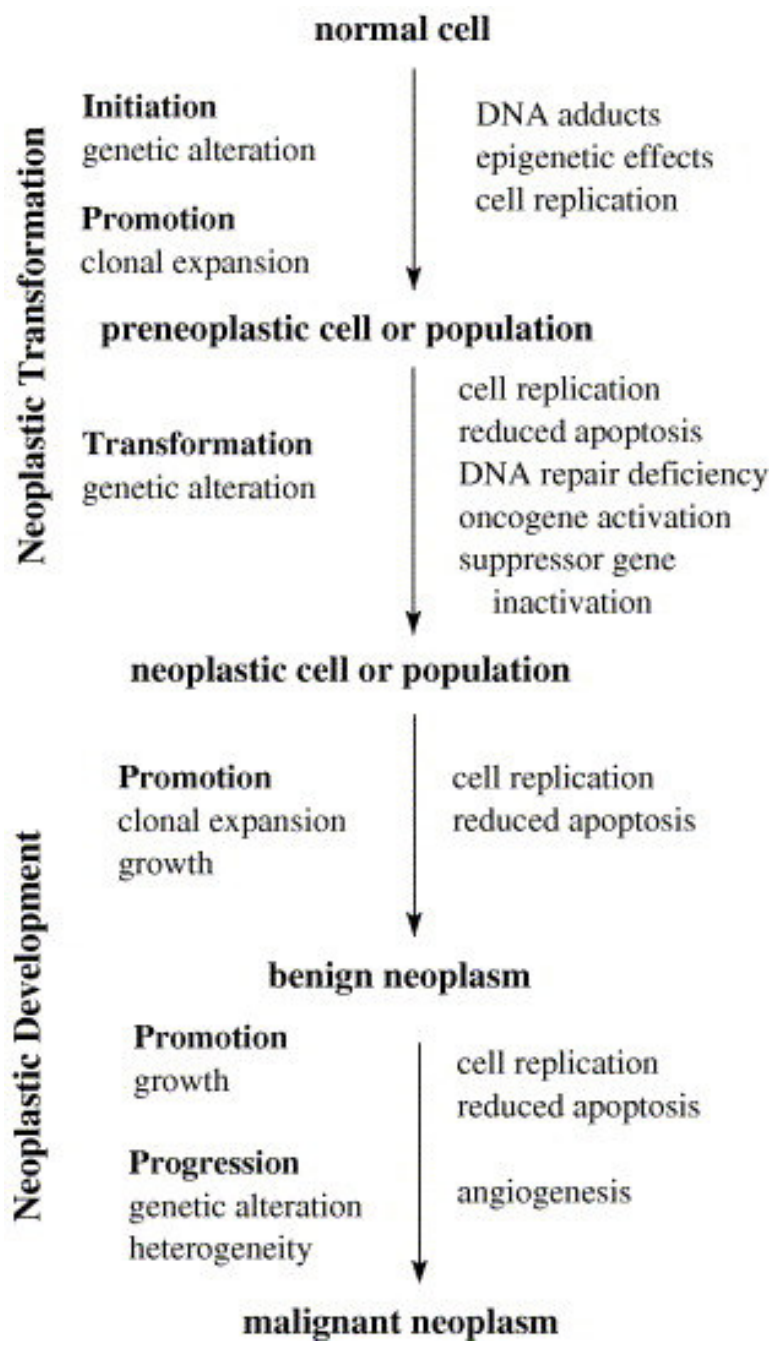

Fig. 1. Sequence of carcinogenesis.

This report specifically addresses an important group of carcinogens in food: DNA-reactive genotoxic carcinogens, i.e. those that have the property to react with DNA in the target tissues and thereby exert mutagenicity. The mode of action of such carcinogens is considered to be relevant to humans (Preston and Williams, 2005). Historically, DNA-reactive carcinogens have been considered not to have a threshold in the dose-response relationship, i.e. theoretically, there is not a dose or intake below which there is zero risk. Such carcinogens are generally bioactivated to electrophiles that react in target tissues with DNA and other macromolecules. In contrast, it is generally considered that a threshold exists in the dose-response relationship for compounds that produce cancers via a non-DNA-reactive mechanism. DNA reactivity is usually inferred from positive results in short-term tests for genotoxicity, but is rigorously established only by measurement of covalent DNA binding.

DNA-reactive carcinogens have long been known to be present in the human diet (Jeffrey and Williams, 2005). Most problems with DNA-reactive carcinogens in food arise from chemicals that are either natural food constituents (such as ethyl carbamate) or contaminants (such as acrylamide, heterocyclic amines, polycyclic 
aromatic hydrocarbons and heterocyclic amines such as PhIP (2-amino-1-methyl6-phenylimidazo[4,5-b]pyridine)), which are formed during cooking processes or by fungal toxins (such as aflatoxins) because they cannot be completely eliminated from the human diet unless the food itself is banned. Compounds that are incorporated into food intentionally, either directly (e.g. additives) or indirectly (e.g. residues of processing aids, pesticides, veterinary drugs or migrants from food contact materials) are assessed for their genotoxic and carcinogenic potentials prior to marketing, and compounds that might be DNAreactive carcinogens would not be permitted.

\section{Problem formulation}

The steps involved in risk assessment are the same for all chemicals in food: hazard identification, hazard characterisation, exposure assessment and risk characterisation (Barlow et al., 2002a, Barlow et al., 2002b and Renwick et al., 2003). Problem formulation precedes the above steps and establishes the context and goals of the risk assessment. A plan needs to be developed, which clarifies the management goals, the purpose and scope of the assessment, the resource implications and timeline, prior to collecting, summarising and assessing data related to the potential hazards and exposures associated with the problem to be addressed. This plan should reflect input from all relevant stakeholders, i.e. risk assessors and managers, consumers, manufacturers or producers, etc.

The nature of the advice to risk managers with regard to the assessment of the potential human health impact due to the (possible or known) presence of a genotoxic carcinogen in food will be determined principally by

(i) the outcome of a problem formulation process in which the issues and questions are defined and the plan for assessing and describing risk is developed (Renwick et al., 2003) and

(ii) the key elements of the risk characterisation that are relevant to address those issues and questions.

Risk characterisation of exposure to chemicals in food and diet involves comparing the estimated human intake with the dose-response data that were assessed in hazard characterisation. The output of risk characterisation can take various forms, including,

(i) determination of a health-based guidance value, such as an acceptable daily intake (ADI) or tolerable daily intake (TDI) (following the identification of a no observed adverse effect level and the application of an uncertainty factor), which is an intake that is considered to be without appreciable health risk if ingested daily over a lifetime,

(ii) estimation of the margin of exposure as the ratio between the dose-response output from animal hazard characterisation and the human exposure,

(iii) quantification of the projected magnitude of the risk at the level of human exposure, derived from the modelled dose-response relationship.

Traditionally, the first approach to risk characterisation has been adopted for the majority of toxic effects, because there are homeostatic mechanisms that reverse any tendency to produce an adverse change at low doses/concentrations, and toxicity is only seen when homeostatic capacity is exceeded. There is no safety 
concern providing the human intake is less than the health-based guidance value. This approach would not be used for genotoxic and carcinogenic chemicals.

\section{Hazard identification}

The purpose of hazard identification in the present context is to identify whether or not the compound is DNA-reactive either as the parent compound or following bioactivation; in other words whether it likely to be carcinogenic via a mechanism that theoretically may not show a threshold in the dose-response relationship. This knowledge has a major impact on the formulation of advice for risk management, and therefore is a crucial question in the overall risk assessment process. The decision on whether or not the compound is genotoxic via DNA reactivity is often the single most important criterion in selecting between a nonthreshold or a threshold approach, respectively, to hazard characterisation. Compounds that produce cancer via a non-genotoxic mechanism, such as $d$ limonene or butylated hydroxyanisole (BHA) or act via a genotoxic mechanism that would show a threshold (see later) would be assessed by determination of the no-observed adverse effect level and the application of uncertainty factors to derive an acceptable daily intake or a tolerable daily intake (Edler et al., 2002).

Therefore, key issues relate to:

- evaluation of DNA-reactive genotoxic potential and

- evaluation of DNA-reactive carcinogenic potential.

In evaluating the evidence for a carcinogenic effect of a chemical, the criteria first developed by WHO (1974) are still used (Williams and Iatropoulos, 2001), which include mainly the induction of a types(s) of neoplasm not found in controls or an increase in exposed animals of a type(s) of neoplasm found in controls. In addition, the early appearance of pre-neoplastic lesions has been taken as evidence of a carcinogenic potential (Williams, 1999). Findings of induction of malignant neoplasms with short latency periods in more than one species, and in several organs are highly suggestive of a DNA-reactive mode of action. On the other hand, induction of tumours in only certain organs, such as endocrine responsive organs, is suggestive of a non-genotoxic mode of action (Williams and Iatropoulos, 2001).

There are two critical questions to be answered in defining a compound as having the potential for both DNA-reactive genotoxicity and carcinogenicity:

- Using a weight of evidence approach, what is the body of evidence that the compound is a DNA-reactive genotoxicant?

- Using a weight of evidence approach, what is the body of evidence that the compound is a carcinogen?

\subsection{What is the evidence that the compound is a DNA-reactive genotoxicant?}

The first question is: "Is the chemical genotoxic and DNA-reactive, i.e. does it form a covalent adduct to DNA, or is it genotoxic but not DNA-reactive or is it non-genotoxic?" This can be a complex issue and the answer may have a profound effect on the approach adopted to hazard characterisation and risk assessment. 
The overall decision is made on weight of evidence, considering information from various sources, none of which is sufficient alone. There are two main criteria and two supporting criteria:

Main criteria:

- Is the compound genotoxic in standard in vitro or in vivo genotoxicity assays?

- Is there evidence related to the mode of action by which the compound interacts with DNA?

Supporting criteria:

- Is the chemical structurally related to other known DNA-reactive genotoxic carcinogens?

- Are there any mechanistic data to support an argument for or against DNAreactive genotoxicity?

\subsubsection{Is the compound genotoxic in standard in vitro or in vivo genotoxicity assays?}

Genotoxicity testing is conducted within a tiered testing strategy (US FDA Redbook, 2000 and Committee on Mutagenicity, 2000). The well-established, extensively validated assays take precedence over others. Initially, in vitro assays are conducted to cover the three endpoints of concern: gene mutation, structural and numerical chromosome aberrations. Normally the testing strategy consists of assays for bacterial mutation, in vitro chromosome aberration, mammalian cell gene mutation and/or in vitro micronucleus formation. Dependent on human exposure, or evidence of mutagenicity in vitro, then in vivo rodent assays are performed, such as the bone marrow micronucleus assay and/or the liver unscheduled DNA synthesis assay. The latter is actually a measure of DNA repair in response to DNA damage and thus provides a measure of DNA reactivity. It is recommended to conduct at least two studies in vivo. Generally, a well-conducted in vivo assay would override the in vitro genotoxicity data. Data from genotoxicity studies may show that a compound is genotoxic but not necessarily that it is DNA-reactive. A number of in vitro, and possibly in vivo, genotoxicants are not directly DNA-reactive compounds, and produce genotoxicity via mechanisms that would be expected to show a biological threshold, e.g. via the formation of reactive oxygen species or the induction of numerical chromosome aberrations via interference with the microtubules at cell division (Crebelli, 2000, Henderson et al., 2000, Kirkland and Müller, 2000 and Müller and Kasper, 2000).

\subsubsection{Is there other evidence that the compound can interact with DNA?}

Information from studies that measure direct interaction with DNA (e.g. DNA binding studies and DNA adduct formation) or indirect measures of DNA damage (e.g. the alkaline elution, single cell gel electrophoresis (comet) and DNA repair assays, in the absence of general cytotoxicity) are useful in this respect (Brusick, 2001).

\subsubsection{Is the compound structurally related to other known DNA-reactive genotoxic carcinogens?}


Do structure-activity relationships relate the structure, sub-structure or chemical class of a compound to other known carcinogens (e.g. other polycyclic aromatic hydrocarbons may be like the DNA-reactive genotoxic carcinogen benzo(a)pyrene)?

\subsubsection{Are there any mechanistic data to support an argument for or against DNA-reactive genotoxicity?}

Information on the metabolic fate and mechanism of action of the compound will indicate whether it is a DNA-reactive genotoxicant, e.g. the mechanism of action of nitrosamines is known and understood and is related to their carcinogenicity. However, others, such as topoisomerase II inhibitors, appear to act indirectly by disturbing DNA structure and function. Mechanistic data are likely to be specific to the compound or its chemical class.

Once all available data are collated and considered as a package, a weight-ofevidence decision can be made on whether a compound is a DNA-reactive genotoxicant.

\subsection{What is the evidence that the compound has carcinogenic activity?}

The second question is "Is the compound a carcinogen?" This can also be a complex issue, particularly if the data set is incomplete. This decision is often based on neoplasia/tumour findings in a standard two-year carcinogenicity bioassay in rodents, but other data can provide the basis for, or contribute to, the overall conclusion (in a weight of evidence approach).

The main data sources for a decision relate to the following questions:

- Is the compound carcinogenic in a standard two-year bioassay for carcinogenicity?

- Is it carcinogenic in alternative cancer bioassays, e.g. the transgenic rodent models $p 53^{+--}, \mathrm{Xpa}^{-/-}$, rasH2 or TgAC? (Data from different models may provide useful information on the mode/mechanism of action of a carcinogen).

- Do epidemiological data indicate an association between exposure to the compound and cancer incidence?

\subsubsection{Is the compound carcinogenic in a standard two-year bioassay for carcinogenicity?}

The most definitive source of information is a well-designed two-year bioassay for carcinogenicity (Williams and Iatropoulos, 2001) in which adequate doses were tested in a sufficient number of animals and appropriate organs were taken for histopathological analysis. Issues may arise from the use of highly inbred rodent strains, with a high background incidence of strain-specific tumours (e.g. liver tumours in $\mathrm{C} 3 \mathrm{H}$ mice), or tumours arising from mechanisms not present in humans (e.g. a2u-globulin mediated kidney tumours in male rats).

\subsubsection{Is the compound carcinogenic in alternative cancer bioassays?}

Recently, novel transgenic animals have been developed to provide carcinogenicity data within a period of 6-9 months. These include the $p 53^{+/-}$, $\mathrm{Xpa}^{-1-}, \mathrm{rasH} 2$ and $\mathrm{TgAC}$ mouse models. These assays are still the subject of some 
development and/or validation (see MacDonald et al., 2001), although data have been accepted by some regulatory authorities.

\subsubsection{Do epidemiological data indicate an association between exposure to the compound and cancer incidence?}

Epidemiological data may be available for chemicals with a long history of use. Epidemiological studies require careful assessment, as many are retrospective studies, relying on memory recall of the exposure, and are confounded by coexposures to other carcinogenic agents, such as tobacco smoke. Nonetheless a well-conducted, accepted epidemiology study can provide useful information on the carcinogenic activity of a compound in humans. Negative studies, however, may lack sufficient power to draw conclusions.

A supplementary question would provide supporting information:

\subsubsection{Does the compound induce pre-neoplastic lesions, such as altered hepatic foci?}

Pre-neoplastic lesions may be present in other toxicity assays conducted on the compound, e.g. sub-chronic toxicity studies, or in dedicated studies to investigate this endpoint (Williams, 1999). Provided the relationship between the lesion and eventual tumour formation is understood, such studies can be taken as indicative of tumour potential over a longer period of treatment.

Data from one of the above main sources of information may be sufficient for a decision on carcinogenicity to be made whilst data on the induction of preneoplastic lesions may provide useful supporting evidence. It should be noted that the above will not distinguish between a genotoxic and a non-genotoxic carcinogen.

\section{Hazard characterisation}

Key questions for hazard characterisation are:

- Based on the mode of action and site of tumourigenesis, are the tumours relevant to humans?

- Are the existing (toxicokinetic- and/or toxicodynamic) data sufficient to reach a conclusion about the likely shape of the dose-response curve for the carcinogenic effect?

- Are there data in addition to those from traditional genotoxicity studies that contribute to the understanding of a genotoxic mode/mechanism of action?

-What is the influence of non-genotoxic processes, e.g. hyperplasia?

- Do data exist to suggest that there may be one or more sub-populations with special sensitivity/susceptibility to the carcinogenic effect of this agent (e.g., as determined by life-stage, gender, genetic polymorphisms, etc.)?

The weight of evidence approach uses all the available toxicological, metabolic and physico-chemical information about a compound for judging the likely potency of the compound in humans. ${ }^{3}$ For DNA-reactive genotoxic carcinogenic compounds in food, hazard characterisation usually has to rely on data from 
animal cancer bioassays. There are inherent difficulties in using potency estimates from such studies because of species differences in the underlying biology, and because very high doses are tested to compensate for the low number of animals that can be used per dose group. ${ }^{4}$ There are large differences in the carcinogenic potency of various genotoxic carcinogens in animals, which span several orders of magnitude, and hence in the likely risk to humans at a given exposure level. For example, numerical descriptors of carcinogenic potency, such as the TD50 (dose equivalent to $50 \%$ of animals remaining tumour free after two years of exposure to the compound, Peto et al., 1984), range in value from $\mu \mathrm{g} / \mathrm{kg}$ bw/d up to $\mathrm{g} / \mathrm{kg}$ bw/d.

\subsection{Toxicokinetic considerations}

The processes of absorption and distribution of an ingested carcinogen are important in determining the amount of the compound or its active metabolite delivered to its site of action. Biotransformation is of major importance because it is usually responsible for

(i) the inactivation and elimination of genotoxic chemicals and/or

(ii) the bioactivation of procarcinogens (chemicals where the parent compound is inactive) to the active genotoxic moiety, and the subsequent detoxication of that chemical species and/or

(iii) the elimination of procarcinogens via pathways that result in detoxication rather than bioactivation.

The majority of DNA-reactive genotoxic carcinogens detected in food are procarcinogens. Compounds that bind directly with DNA without the need for metabolic activation are chemically reactive molecules; such compounds are likely to be unstable within a food matrix because they would interact with components of the matrix thereby losing their reactivity. Such molecules are unlikely to be detectable in their reactive form in food matrices.

The rate of absorption from the gastrointestinal tract can be influenced by the mode and vehicle of administration, with higher rates of absorption generally occurring under fasting conditions and following gavage administration in solutions (Renwick, 2001). Administration by incorporation into animal feed can reduce the rate of absorption, and hence the potential for depletion of cytoprotective factors such as glutathione (see below). The slowest rate of absorption is likely to occur when the chemical is present within a food matrix, and this complicates the estimation of the risk to humans exposed via the diet when this is based on dose-response data from animal studies (Dybing et al., 2002). First-pass metabolism within the gut lumen, gut wall or liver can result in extensive detoxication of reactive chemicals present in food, and a steep increase in response may occur at doses that saturate the enzymes responsible. In contrast, first-pass metabolism may contribute to the bioactivation of procarcinogens to the active chemical species, and saturation of this process could lead to a shallower dose-response at high intakes.

Reactive genotoxic compounds and the reactive electrophilic metabolites of procarcinogens form covalent bonds with DNA, as a part of their mechanism of action, and also with macromolecules such as proteins. Covalent protein binding reflects the extent of internal exposure to the reactive chemical species and evidence of non-linearity in exposure to the reactive chemical species can be obtained by measurement of biomarkers such as protein adducts. 
Biotransformation determines the rates and extents of formation of any biologically reactive intermediates, and of the detoxication of the reactive chemical species, whether it is the parent compound or a metabolite (Oesch et al., 2000 and Swenberg et al., 2000). Elimination of reactive carcinogens and procarcinogens occurs primarily via metabolism in the liver and this determines the concentrations in the circulation and delivered to the target tissue, the duration of exposure following a single dose and the extent of accumulation of repeated dosage. Species differences in carcinogenic potency can arise from differences in the extent of metabolic bioactivation. Metabolism within the target tissue can be important in the local production of highly reactive chemical species, which would not survive in the blood and therefore cannot be delivered via the circulation. Local target-organ detoxication of reactive species is also of critical importance, whether the reactive species is produced locally or delivered via the circulation. The detection of acrylamide in cooked food acted as a major stimulus for the recent discussions within EFSA, WHO and ILSI Europe. It is a good example of the importance of metabolism in carcinogenicity, because it undergoes oxidative metabolism to the active entity, glycidamide, which binds to DNA and is inactivated by reaction with glutathione (JECFA, 2005).

Enzyme-catalysed reactions have a finite capacity for interaction of the chemical with the protein. At low concentrations the rate of catalysis is proportional to the substrate concentration, and therefore inherently linear with respect to dose or concentration. At high concentrations of the chemical, all of the specific sites on the enzyme may be occupied and addition of further chemical cannot result in increased metabolism. Saturation of metabolism within the target tissue is of considerable importance in the context of genotoxic carcinogens. Species differences in the concentrations associated with saturation of metabolism are likely, because of differences in $\mathrm{Km}$ values, which could influence the doses/concentrations associated with non-linearity in humans and in experimental animals (Andersen, 2003).

At high substrate concentrations the extent of a chemical reaction can result in the depletion of cofactors such as glutathione, and under these circumstances the rate of reaction may become dependent on the available concentration of the cofactor. At low doses of a genotoxic carcinogen, the concentrations of the cofactor will be in a vast excess, and the rate of detoxication is directly proportional to the concentration of the carcinogen. Saturation of the main pathway(s) of detoxication of a procarcinogen may result in metabolism by normally negligible routes, via enzymes with much higher $\mathrm{Km}$ values; this could result in significant metabolic activation to the DNA-reactive species only at high intakes causing, in effect, a threshold in the dose-response relationship. Concentrations sufficient to saturate metabolic pathways are far more likely in high-dose animal carcinogenicity studies than following human exposure to environmental or dietary concentrations of carcinogens. In consequence there is a greater potential for non-linearity in animal studies than in human epidemiology studies involving dietary exposures (Swenberg et al., 1995).

Hepatic enzyme induction has been observed in many rodent toxicity studies. Induction of a bioactivation process would result in a non-linear increase in the amounts of a reactive metabolite, whereas induction of a detoxication process would produce a shallower slope at higher doses. Enzyme induction is an effect that is seen at high doses and therefore is less likely at low levels of human intake.

There are genetic polymorphisms in some of the enzymes involved in the biotransformation of foreign chemicals (Nebert et al., 1996). Polymorphisms 
could affect the risk from compounds that are genotoxic and carcinogenic (Vineis, 2004). Individuals with an enzyme deficiency could show higher sensitivity if the defect is in a major elimination or detoxication pathway or lower sensitivity if it is in the enzyme responsible for bioactivation. A number of studies have explored the relationship between genotype and cancer risk, but findings are often inconsistent (Lewis et al., 2002) and any effect seems to be only up to a doubling of risk (D'Errico et al., 1999). Neonates and very young infants have low activity for some of the enzymes involved in foreign compound biotransformation and theoretically this could influence sensitivity (Dorne et al., 2005).

\subsection{Toxicodynamic considerations}

At the low intakes typical of food-borne genotoxic carcinogens the probability of cancer may not be linearly related to the dose, even if the internal dose is linearly proportional to the external dose. The argument for a linear dose-response, which is often assumed for genotoxic carcinogens, is based on the probability that a single critical cellular event may or may not occur (with a given probability). However, it is now known that more than one critical process (mutation) is needed for a cell to be transformed into a malignant cell (Hanahan and Weinberg, 2000). A sequence of consecutive critical events will tend to make the doseresponse less linear (more sigmoidal) than would a single critical event, as can be seen by comparing the single-hit model with the multi-stage model. In addition, mutated (intermediate) cells are not immortal, and they may die before undergoing another mutation. The process of clonal expansion of intermediate cells, and the possibility that an intermediate cell (or their clones) may die out, is incorporated in the MVK (Moolgavkar, Venzon and Knudson) model of carcinogenesis (Moolgavkar and Luebeck, 1990). This model shows that even when it is assumed that mutation rates are proportional to dose, the resulting dose-response relationship can be non-linear. The sequence of changes also explains why observed DNA adducts can be linearly related to dose, while the observed cancer incidences are not.

At high doses, DNA repair may be unable to eliminate all miscoding adducts prior to the affected cell entering the phase of DNA synthesis, resulting in an increased probability of mutation per DNA adduct (Tong et al., 1980). If this were to occur at dose levels associated with increased tumour incidences in animal studies at lower doses, then the tumour probability would be non-linear. In addition, accompanying toxic effects, such as increased apoptosis, cell proliferation and interference with cell cycling, may have an impact on tumour probability (Williams et al., 2000). Such epigenetic events would be less likely to occur at low doses, which are typical of exposures to food-borne genotoxic carcinogens (Williams et al., 2005).

The toxicodynamic considerations are difficult to quantify, but they all point in the same direction, i.e. that the tumour incidence at low intakes would not be proportional to that at high administered doses in carcinogenicity studies, and the dose-response would be essentially sub-linear.

In humans, genetic differences exist in some of the enzymes involved in DNA repair (Myrnes et al., 1983) and in elements that regulate cell cycling and death (Balmain, 2002). Such differences could affect the risk from compounds that are genotoxic and carcinogenic; an example is the high susceptibility of individuals with xeroderma pigmentosum (deficient in DNA repair) to sunlight-induced skin cancer and neoplasias in other tissues (Hoeijmakers and Bootsma, 1990). Nevertheless, the evidence presently available indicates that any increase in risk related to variability in DNA repair is in the range of 2-6 fold (Mohrenweiser, 
2004). Neonatal and young animals show higher sensitivity to the carcinogenic effects of some chemicals (National Cancer Institute, 1979), probably because of higher rates of cell proliferation; whether this is the case for human neonates and infants is not known, but greater sensitivity towards such chemicals would be expected.

\subsection{Dose-response assessment}

As discussed above, genotoxic carcinogens are considered to cause cancer by a stochastic process. In theory, a single active species entering the cell might hit the DNA, which might lead to a mutation (or be repaired), and which might be a cancer-relevant mutation. Whether such events take place may be regarded as the outcome of chance. Thus, each single molecule entering the cell has a certain (albeit extremely small) probability of resulting in a cancer-related mutation. Theoretically, the overall probability that a given internal dose causes a relevant mutation may then be expected to be proportional to that dose (total probability $=$ product of probabilities per molecule). If this hypothetical scenario were true, then there should be a linear dose-response for all genotoxic carcinogens, at least in the low-dose region. Clearly, at higher tumour incidence the curve has to bend to $100 \%$, and therefore the dose-response relationship in the range of observation cannot be linear, but the real question is whether or not the dose-response relationship is linear in the low-dose range, where tumour incidences are low enough to be relevant to risk assessment. Unfortunately, incidences of interest for risk assessment may be as low as $10^{-6}$, which is far beyond the range of observation in animal or epidemiological studies. Therefore, the shape of the low-dose-response relationship cannot be determined from data: it can only be deduced from theoretical considerations or indirect evidence. Such evidence may be available from toxicokinetic and/or toxicodynamic perspectives.

\subsubsection{Dose-response analysis of epidemiological data}

For the purpose of estimating human cancer risks, the most reliable dose response data would be obtained from good epidemiological studies in human populations for which both the exposure level to a given genotoxic carcinogen and the observed corresponding tumour incidence are known. Any confounding factor, such as co-exposure to other toxic factors, would need to be taken into account. Using such data, extrapolation over only a relatively narrow dose range would be necessary to quantify human risks at lower exposure levels. Such a situation is very rare and even in the best available examples of epidemiological data (e.g. aflatoxin $B_{1}$ ) various problems prohibit clear-cut conclusions (for details see JECFA, 1998).

\subsubsection{Dose-response analysis of data from cancer bioassays in rodents}

Quantitative extrapolation of animal tumour incidences observed at high doses over many orders of magnitude down to the much lower dose levels that are relevant for human risk assessment, incorporates numerous uncertainties. The biological arguments discussed above may provide indirect evidence that the dose-response is likely to be sub-linear, but it is not possible to predict whether this might be the case or to determine the slope at the low intakes relevant to risk assessment. Each of the processes discussed might have their impact within the observable range of tumour incidences, or far below it. Therefore, the conclusion that the dose-response relationship is probably sub-linear does not give practical guidance, except that a linear dose-response could be regarded as a conservative assumption. 
Mathematical analysis of the dose-response data from an animal bioassay can be used to define the intake necessary to produce a given level of response, such as $10 \%, 25 \%$ or $50 \%$ cancer incidence. The intakes of different compounds giving the same level of response reflect the relative potencies of the compounds. Various methods are available to define a reference point on the intake-response curve, such as the benchmark dose (BMD), the lower confidence interval on a benchmark dose (the BMDL), the T25 (Dybing et al., 1997) or the TD ${ }_{50}$ (Peto et al., 1984). The BMD approach is being used increasingly, with a $10 \%$ cancer incidence being used most frequently as the benchmark response (EFSA, 2005 and JECFA, 2005). The reference point derived from the animal bioassay can be used in three ways:

(i) To compare the potency of different compounds. Data from animal bioassays can be used to rank carcinogenic potency without reference to human intakes. In the past, many attempts have been made to rank carcinogenic substances by their potencies in animal bioassays. For example in a series of publications Gold et al. tabulated data on a large number of compounds allowing their carcinogenic potency to be expressed as the $\mathrm{TD}_{50}$ (Gold et al., 1999). The T25 or BMDL10 approaches may also be used for potency ranking. These values can be used to indicate the relative potency of a series of compounds.

(ii) To extrapolate the incidence down to the level of human exposure or to estimate an intake that would give a very low risk (see Section 6.2.2).

(iii) To compare directly with the level of human exposure by calculation of the margin of exposure (see Section 6.2.3).

\title{
5. Intake assessment
}

Intake scenarios for genotoxic carcinogens in food will almost always concern naturally occurring substances, illegal additives or substances formed during cooking or processing, since substances authorised for deliberate addition to foods, such as food additives, would generally exclude genotoxic carcinogens. In any food chemical risk assessment, exposure assessment is often a source of great uncertainty (Kroes et al., 2002 and Renwick et al., 2003). This problem may be more pronounced in the case of genotoxic carcinogens in foods due to the low concentrations in foods, variability in concentrations, and variability in foods consumed. In its simplest form, food chemical intake assessment may be expressed as:

\author{
Intake of a chemical in a food item \\ $=$ concentration in food item \\ $x$ amount of food item consumed
}

Total dietary intake is the sum of intakes from all the food items containing the chemical. Intake data may be based on projected estimates or on data collected in food surveillance studies.

There is still considerable lack of harmonization in relation to the conduct of food chemical intake studies although the situation is improving rapidly. Comparison of data may be difficult among different studies. When based on analytical measurements and food consumption data, consistent identification of the food items consumed through the use of food codes is important, as this is the means 
by which analytical data are combined with food consumption data. Thus, there are two distinct elements to the estimation of dietary intakes: analytical measurement of the chemical in foods; and measurement of intakes of foods that may contain the chemical.

\subsection{Measurement of the chemical in foods}

The low levels at which genotoxic carcinogens may be present in foods may present special challenges to the analytical technology used. It is important that validated standard methods be employed where possible, that laboratories participate in an external proficiency-testing scheme and that third party accreditation is employed. It may be appropriate to establish the fitness for the purpose of the analytical method selected for the problem identified in the problem formulation step. For example, it may be preferable to screen all substances having a similar mode of action (e.g. PAHs) rather than conducting expensive measurements on individual substances. Detailed guidelines are available elsewhere on the handling of food analytical data for the purpose of risk assessment (WHO, 1995, Douglass and Tennant, 1997, Barlow et al., 2002a, Barlow et al., 2002b, Petersen, 2002 and Renwick et al., 2003). WHO (1995) recommended that the majority of analytical effort is targeted at foods contributing the first $85 \%$ of a contaminant. Monitoring should concentrate on appropriate dietary staples that are likely to be the major sources of intake. Distinct geographic regions or ethnic food consumption patterns may necessitate different monitoring plans.

Genotoxic carcinogens may not be evenly distributed in the food matrix. Regions of high concentration may arise, inter alia, due to surface mould contamination (e.g. aflatoxin $B_{1}$ ), portions receiving higher heat such as the crust of bread (e.g. acrylamide), or the fried surface of meat (e.g. benzo(a)pyrene or PhIP). Similarly, for many of the genotoxic carcinogens generated during domestic cooking or industrial processing such as acrylamide, PAH and PhIP, the cooking method or process will greatly influence levels in the food as consumed (for example, grilling versus frying). Pertinent information should be collected during the acquisition of food consumption data. It is essential that foods analysed are representative of foods consumed by the population(s) or sub-populations of interest. Surveillance data are available for many countries. Such data are generally updated annually and are often obtained to ensure compliance with food legislation (for regulated contaminants). In duplicate diet studies a duplicate portion of all foods consumed during the study period is analysed. Such studies are labour intensive and expensive. However, by directly analysing the foods consumed by subjects in such studies, uncertainties related to both food consumption data and concentration data are minimised.

\subsection{Measurement of the intakes of foods that may contain the chemical (food consumption data)}

Food consumption data may be obtained by three broad approaches: food supply data, household data and individual food consumption surveys.

\subsubsection{Food supply data}

Food supply data measure the availability or disappearance of foods on a national or regional basis each year giving an estimate of mean per capita consumption. Although such data are crude compared with individual food consumption studies, they may be the only form of data available for some countries and can facilitate comparison of dietary exposures for different countries and regions. The WHO 
GEMS/Food programme (www.who.int/foodsafety/chem/gems/en/index.html) prepared a series of regional diets for conducting risk assessments based on food supply data. Exposures to some genotoxic carcinogens in foods (e.g. aflatoxin $B_{1}$ ) show marked regional variations which may be compared using food supply data in conjunction with appropriate food analysis data.

\subsubsection{Household data}

In their simplest form, household surveys may be regarded as an extension of national food supply surveys applied at household level. Detailed household data are available for many countries. While much useful detail can be contained in such data, food waste is generally ignored, the individuals consuming the foods are not identified and foods consumed outside the home are not measured.

\subsubsection{Individual food consumption surveys}

The most accurate food consumption data are acquired in studies of individual food consumption. Such studies include

- Food frequency questionnaires

- Food recall surveys of past consumption

- Food diaries about current consumption

Food frequency data allow only a qualitative estimate of exposure and are of limited utility for the accurate estimate of chemical intakes. Food recall data depend on the memory of the respondent and quantities are estimated. Food diaries such as seven day weighed intakes provide quantitative data on foods consumed but are labour intensive and can only be applied to limited numbers of individuals.

Whichever method is used to derive food consumption data, risk characterisation for genotoxic carcinogens usually involves the combination of lifetime animal potency data with short-term human intake estimates. It is therefore important to establish that the data produced are representative of the pattern of chronic exposure and of exposure among sub-populations of toxicological interest.

Mean or median exposures may be calculated easily from simple food analysis and food consumption data. Crude intake scenarios may be calculated from the range of concentrations in foods and the range in food consumption data. Although not yet fully accepted by regulatory authorities, probability distributions are increasingly being generated using probabilistic analysis such as Monte Carlo modelling. Such methods facilitate the estimation of exposure percentiles such as the 90th, 95th, 97.5th or even up to 99.9th percentiles. However, it is recommended that the plausibility of estimated high percentile intakes is checked against corresponding food consumption data before accepting the output from statistical analysis. The following questions are pertinent to an exposure assessment:

- In what food(s) is/could this genotoxic carcinogen be present?

- Are there any sub-populations that are high consumers of the foods concerned? 
- What is the exposure pattern for consumers considered to be sensitive (which could be determined by life-stage, gender, genetic polymorphisms, etc.)?

- Is the intake taking place every day, or only infrequently? Information on patterns of exposure may also be useful to risk managers. See Slob et al. (2006) for a quantitative approach for describing intermittent intakes. This information should be assessed during the risk characterisation process.

- Are there non-food sources and/or other routes of exposure to this substance that should be taken into account in the risk characterisation?

\subsection{Biomarkers of exposure}

For substances present at very low concentrations in the diet, bioavailability from food matrices is an important consideration. It may be possible to simulate the effect of food matrices on intestinal absorption by studies in vitro. Biomarkers of exposure have been applied to several genotoxic carcinogens in the diet and facilitate the calculation of internal doses, which can be compared with estimated dietary intakes. Some biomarkers, such as protein adducts, permit the integration of exposure over a period of time as opposed to a single point measurement. Biomarkers may give very accurate estimates of exposure by individuals in research studies but have limited utility at a population level.

\section{Risk characterisation}

Risk characterisation has been defined as "the quantitative or semi-quantitative estimate, including attendant uncertainties, of the probability of occurrence and severity of adverse effect(s)/event(s) in a given population under defined conditions based on hazard identification, hazard characterisation and exposure assessment" (European Commission, Scientific Steering Committee, 2000). At its best, a risk characterisation "synthesises an overall conclusion about risk that is complete, informative and useful for decision makers" (US Environmental Protection Agency, 2000).

As noted by Renwick et al. (2003), the advice to risk managers may be qualitative or quantitative, depending upon the outcome of problem formulation, data availability and the nature of the compound. The usual hazard characterisation approach for compounds that cause cancer by non-DNA-reactive mechanisms is to calculate a health-based guidance value, such as a tolerable daily intake, using the no-observed adverse effect level and uncertainty factors. Such an approach is not used for compounds that cause cancer by DNA-reactive mechanisms. The decision-making environment also may dictate the nature and focus of the advice. Depending upon the circumstances, risk managers could be presented a risk characterisation containing only a qualitative judgment of risk. Alternatively, the risk characterisation may include one or more quantitative estimates of risk in addition to the qualitative judgement.

Whichever method of risk characterisation is adopted, the output is only as reliable as the quality of the data used. This applies to all data used, i.e. hazard identification, hazard characterisation and dose-response analysis and exposure estimation (Fig. 2). 


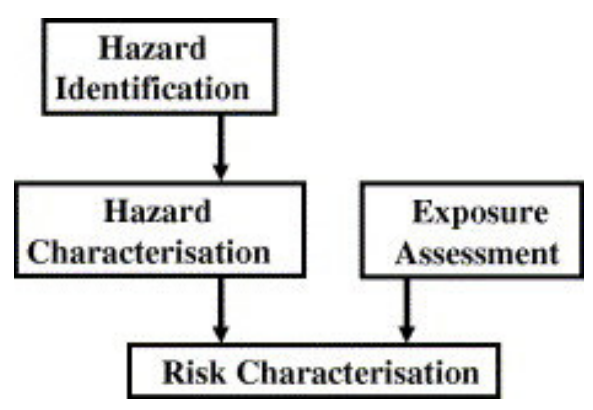

Fig. 2. The incorporation of data on toxicity and exposure into risk characterisation.

\subsection{Qualitative approaches}

The only data essential for qualitative approaches, such as ALARA (as low as reasonably achievable), is identification of the compound as a genotoxic carcinogen. An important decision is that the genotoxicity arises via direct covalent binding to DNA, rather than via a mechanism that would show a threshold in the dose-response relationship. Often data are available from a variety of genotoxicity tests and the decision is based on a weight of evidence approach, which takes into account the quality of the available data.

Although the ALARA principle is an easy to understand concept, it poses some major difficulties for the risk manager as it does not discriminate between very potent and very weak carcinogens and does not take human exposure into account. It does not give any guidance on the magnitude of any risk that might be associated with a given "reasonably achievable" low exposure level. Although these difficulties would point to the alternative approach of calculating the intake levels associated with "acceptably small risks", the mathematical models necessary may give widely divergent answers and do not provide a reliable basis for the formulation of realistic risk management advice.

\subsection{Quantitative approaches}

Quantitative approaches combine data from the dose-response relationship defined by an epidemiology study or a cancer bioassay with an estimate, or estimates, of exposure. In consequence, the reliability of the estimate is dependent on the quality of the data used to identify and characterise the hazard and the data used to define the exposure. Limited data for any element of the risk assessment process (Fig. 2) will add uncertainty to the output and any numerical value is only as precise as the underlying data allow.

There are basically three different approaches that can support the formulation of quantitative/semi-quantitative advice to risk managers. These are the application of the TTC approach (Section 6.2.1), extrapolation of the available animal doseresponse data to the level of human exposure (Section 6.2.2) and calculation of the margin of exposure (MOE) (Section 6.2.3). Application of the TTC approach requires chemical-specific data on intake only, because the dose-response data are derived from studies on structural analogues, whilst quantitative risk estimation and calculation of the MOE use chemical-specific data on both doseresponse and human exposure.

\subsubsection{Threshold of toxicological concern (TTC) for low-dose exposure in special circumstances}


A particularly difficult situation arises when a compound that is present in human food has been shown to be a direct-acting genotoxicant, but either there are no data from a cancer bioassay or the carcinogenicity data fail to define the doseresponse relationship, for example because the only dose studied gave a $100 \%$ incidence.

Under such circumstances, it may be possible to apply the TTC concept to extremely low exposures using data from cancer bioassays on chemicals in the same structural class. Although there is a general consensus that it is not possible to define an intake for a DNA-reactive carcinogen that would give a zero risk, the threshold of toxicological concern (TTC) concept provides a practical and conservative approach that could be used to formulate advice to risk managers when exposures are very low (Kroes et al., 2004). The TTC concept has been used for a number of years for the risk assessment of chemicals with various structural characteristics that may be present in food at very low levels, such as packaging migrants and flavouring substances. In the context of genotoxic chemicals, TTC values were proposed by Kroes et al. (2004) for chemicals with structural alerts for both genotoxicity and carcinogenicity. The values were based on the daily intake estimated to give a lifetime risk of less than one in a million, using the highly conservative approach of linear extrapolation from the $T_{50}$ values derived from the dose-response data from rodent cancer bioassays on all structurally related compounds studied in rodent cancer bioassays. Analysis of the potency data for genotoxic carcinogens with different structural alerts indicated that a practical TTC could not be set for aflatoxin-like, azoxy-, or nitrosocompounds because of their very high potency. A practical TTC for compounds with other structural alerts for genotoxicity was proposed at $0.15 \mu \mathrm{g} /$ person/day. At that level for compounds with a structural alert indicating a genotoxic carcinogen (excluding aflatoxin-like, azoxy-, and nitroso-compounds) there would be an $86-97 \%$ probability (depending on the structural alert) that any theoretical calculated risk would be less than one in a million if the intake were at or below the TTC. The quality of the exposure estimate is of greatest importance when exposure is close to the TTC value. The TTC approach may be useful as an adjunct to prioritisation of risk management actions (for example in association with ALARA) and/or definition of research priorities.

\subsubsection{Low-dose extrapolation of data from rodent carcinogenicity bioassays}

Numerical estimates of the risk associated with the human exposure can be derived by extrapolation of the animal dose-response data or by the use of the $\mathrm{TD}_{50}, \mathrm{~T} 25$ or BMDL10 as the point of departure for low-dose risk estimation by simple linear extrapolation. These may be expressed either as the calculated additional cancer risk arising from different levels of exposure or as the level of exposure associated with a predefined level of lifetime risk, such as one in a million. Estimation of the possible cancer risk at the levels of human intake has to be based on empirical mathematical models that do not reflect the complexity of the underlying biology. A number of mathematical models have been proposed, and the resulting risk estimates are dependent on the mathematical model used. Using the same dose-response data from an animal study but different mathematical models, the intakes associated with very low risks, such as one in a million, can differ by orders of magnitude.

Linear extrapolation from a point of departure (or reference point, see Section 4.3.2), such as the benchmark dose (BMD), lower confidence interval on a benchmark dose (BMDL) or the T25, is conservative and simple to apply. However, it should be recognised that the output is considered to be an upper 
bound on the risk for rodents and not a mathematical estimate of the real risk for humans. Although calculation of the intake associated with a specified cancer risk (e.g. one in a million) from a high-dose point of departure appears to be a precise mathematical procedure, the assumption of a linear relationship means that this approach does not have a realistic biological basis. When agencies involved in risk assessment estimate the intake associated with a cancer risk of say one in a million, in reality this relates to the risk in the test species and not in humans, unless the dose-response modelling includes a PBTK-model (physiologically based toxicokinetic model) of species differences in target-organ concentrations of active chemical species (and even then toxicodynamic differences will not have been taken into account).

The validity of numerical risk estimates is dependent on the quality of the data used to define the dose-response relationship, the exposure data and also the relevance of the mathematical extrapolation model. The use of epidemiology data has the potential to provide a more valid estimate because the extent of dose extrapolation is less than from an animal cancer bioassay, the problems of interspecies differences are not relevant, and human variability may have been incorporated in the data used.

A major problem with the generation of theoretical numerical risk estimates is that they are open to misinterpretation because they may be regarded as a realistic indication of the actual risk. Although, the numerical estimate is sometimes acknowledged as being an upper bound estimate, and that the lower bound risk may approach zero, risk management actions generally focus on the upper bound.

Finally, simple linear extrapolation methods probably greatly overestimate the real risks (Ames and Gold, 1991) and despite this, the human cancer incidence attributed to the diet by epidemiologists is not explained by known chemical carcinogens in the diet (Lutz and Schlatter, 1992).

\subsubsection{Margin of exposure}

The ratio between a dose leading to tumours in experimental animals and the human intake (see below) is known as the margin of exposure (MOE). The approach can be applied to both individual substances and exposure sources and to chemical classes and aggregate exposures. The magnitude of the MOE reflects but does not attempt to define the possible magnitude of the risk: the larger the $\mathrm{MOE}$, the smaller the risk posed by exposure to the compound under consideration. Calculation of the MOE requires two decisions; defining the point on the dose-response curve, usually from an animal study, to use as the comparator, and the human intake with which it should be compared. The $\mathrm{TD}_{50}$, the T25 (Sanner et al., 2001), or a benchmark dose (Gaylor and Gold, 1998 and Gaylor, 2000) are often taken as comparative estimates of potency of genotoxic carcinogens. The $\mathrm{T} 25$ or $\mathrm{BMD}(\mathrm{L})$ may be used as points of departure (POD) for low-dose risk estimation. Different estimates of human intake provide risk managers with different information, for example the mean or median intake provides a general picture, while the intake by the 90th, 95th or 97.5 th percentile of consumers provides information about the high consumer. Because the MOE is simply a ratio, different MOE values can be estimated for different percentile intakes.

Interpretation of an MOE for a genotoxic carcinogen would be difficult for risk managers, without some advice about the uncertainties, assumptions and limitations present in the data used to derive the ratio. The usual considerations 
of species differences and human variability would be inherent uncertainties when the MOE is based on animal data. Risk managers should be informed of the magnitude of an MOE that could be considered to represent a low priority for risk management actions, after taking into account uncertainties related to the precision of the dose-response relationship and the quality of the human exposure data, which in some cases may be quite poor. There is no established history of the use of MOE for genotoxic and carcinogenic compounds.

The EFSA Scientific Committee considered that an MOE of 10,000 or more, based on animal cancer bioassay data, "would be of low concern from a public health point of view and might reasonably be considered as a low priority for risk management actions" (EFSA, 2005). An exposure potency index (EPI) is used by Health Canada in their Human Health Risk Assessment for Priority Substances under the Canadian Environmental Protection Act (Health Canada, 1994) for compounds that are both genotoxic and carcinogenic. The EPI is calculated as the average exposure in the population divided by the dose in experimental animals that produces a $5 \%$ incidence of tumours. Advice to risk managers on the interpretation of numerical estimates is that: EPI values of $2 \times 10^{-4}$ or more are considered to be a high priority for the analysis of options to reduce exposure; EPI values between $2 \times 10^{-4}$ and $2 \times 10^{-6}$ are a moderate priority; and EPI values less $2 \times 10^{-6}$ are considered a low priority. The biological basis and derivation of these values were not explained. The EPI can be regarded as a reciprocal of the MOE and the reciprocals of the EPI values correspond to margins of exposure of $<5000$ (high priority), 5000-500,000 (moderate priority) and $>500,000$ (low priority).

Despite its limitations, the margin of exposure (MOE), which combines hazard characterisation with exposure assessment, is the most scientifically meaningful form of advice to risk managers, but the MOE would need to be provided with guidance on the quality of the data used and the uncertainties and variables that would be inherent in the comparison of hazard and exposure.

Table 1 presents the calculated margins of exposure for selected food-borne carcinogens. Exposure data are drawn from a number of sources and the calculated margins of exposure against rodent bioassay derived T25 and BMDL10 values show a wide range. High margins of exposure were observed for PhIP and benzo(a)pyrene, whereas the margins of exposure for aflatoxin $B_{1}$ were up to three orders of magnitude lower. The calculations show the potential utility of margins of exposure as a means of providing risk managers with a means of identifying potential priority areas for risk management provided reliable exposure and dose-response data are available. It is interesting to note that all of the examples in Table 1 have estimated intakes that would exceed the TTC value of $0.15 \mu \mathrm{g} /$ day proposed by Kroes et al. (2004) for genotoxic carcinogens (which would exclude aflatoxin $\mathrm{B}_{1}$ and nitrosamines). 
Table 1.

Margins of exposure (MOEs) for selected food-borne carcinogens (see Appendix A for details)

\begin{tabular}{|c|c|c|c|c|c|}
\hline \multirow[t]{2}{*}{ Carcinogen } & \multirow{2}{*}{$\begin{array}{l}\text { T25 } \\
\text { (mg/kg } \\
\text { bw/day] }\end{array}$} & \multirow{2}{*}{$\begin{array}{l}\text { BMDL10a } \\
\text { (mg/kg } \\
\text { bw/day] }\end{array}$} & \multirow{2}{*}{$\begin{array}{l}\text { Estimated human } \\
\text { exposureb,c } \\
\text { (ng/kg bw/day] }\end{array}$} & \multicolumn{2}{|l|}{ MOE $^{\text {b }}$} \\
\hline & & & & T25 & BMDL10 \\
\hline \multirow[t]{5}{*}{ Acrylamide } & 0.65 & 0.31 & 410 (males) & 1600 & 760 \\
\hline & & & 420 (females) & 1600 & 740 \\
\hline & & & 430 & 1500 & 720 \\
\hline & & & 920 & 710 & 340 \\
\hline & & & 2310 & 280 & 130 \\
\hline \multirow[t]{3}{*}{ Aflatoxin $B_{1}$} & $0.50 \times 10^{-3}$ & $0.16 \times 10^{-3}$ & 0.25 & 2000 & 640 \\
\hline & & & 0.3 & 1700 & 530 \\
\hline & & & 2.0 & 250 & 80 \\
\hline Benzo(a)pyrene & $2.4^{\mathrm{d}}$ & 2.0 & $10-15$ & $160,000-240,000$ & $130,000-200,000$ \\
\hline Dimethylnitrosamine & 0.15 & 0.06 & $14^{\mathrm{e}}$ & 11,000 & 4300 \\
\hline \multirow[t]{3}{*}{ Ethyl carbamate } & 1.0 & 0.28 & 20 & 50,000 & 14,000 \\
\hline & & & 70 & 14,300 & 4000 \\
\hline & & & 2000 & 500 & 140 \\
\hline PhIP & 2.0 & 1.25 & $4.8-7.6$ & $260,000-420,000$ & $170,000-260,000$ \\
\hline
\end{tabular}

T25: defined as the daily dose in $\mathrm{mg} / \mathrm{kg}$ bw (obtained by linear extrapolation) inducing a $25 \%$ increase in tumour incidence above background over a life-time exposure (104 weeks used here as default).

BMDL10: defined as the lower 5\% confidence bound on a dose resulting in a $10 \%$ increase in tumour incidence above background, derived by fitting a mathematical model to the experimental potency data.

a Models assumed a maximum response of $100 \%$ at high doses with the exception of dimethylnitrosamine where the response was seen to plateau at an incidence of $\ldots 70 \%$.

${ }^{b}$ These figures are for illustration purposes only; the quality of raw data has not been evaluated.

${ }^{c}$ As intake from food.

${ }^{\mathrm{d}}$ Non-linear dose-response.

e Composite intake of $N$-nitrosodimethylamine and $N$-nitrosopyrrolidine.

The MOE values for acrylamide and benzo(a)pyrene given in Table 1 differ from those derived recently by JECFA (JECFA, 2005) based on BMDL10 values, 
whereas the MOEs for ethyl carbamate are similar. For acrylamide, the difference in MOE arises from a difference in the exposure data used (JECFA used a mean exposure of $1 \mu \mathrm{g} / \mathrm{kg} \mathrm{bw} / \mathrm{d}$ and a high exposure of $4 \mu \mathrm{g} / \mathrm{kg} \mathrm{bw} / \mathrm{d}$ resulting in MOEs of 300 and 75, respectively, which JECFA considered to be low and indicative of human health concern). The literature reports a large variation of acrylamide concentrations in foods. The present analysis used a recent figure for high consumption among children in the USA (a sub-group potentially with high exposure) (see Appendix A). Since acrylamide was discovered to be a thermal byproduct in food in 2002, much research has been dedicated to decreasing levels that has resulted in lower exposure from some products. If such efforts are successful, dietary exposure to acrylamide will decrease, complicating the comparison of dietary exposures calculated at different times. Similarly, the high intake value of $2000 \mathrm{ng} / \mathrm{kg}$ bw/d used herein for ethyl carbamate is an historical intake value based on the consumption of stone fruit brandies and current intakes are much lower. Nevertheless, JECFA considered that while the MOE for the mean intake of ethyl carbamate in foods $(20,000)$ was of low concern, the MOE for food and alcoholic beverages combined (3800) was of concern. This is consistent with the range of MOEs presented for ethyl carbamate in Table 1.

JECFA reported MOEs for average and high intakes of polycyclic aromatic hydrocarbons of 25,000 and 10,000, respectively, which were considered to be of low concern for human health. The difference for benzo(a)pyrene arises largely from a 20-fold difference in the BMDL10 (JECFA $=0.1 \mathrm{mg} / \mathrm{kg} \mathrm{bw} / \mathrm{d}$ benzo(a)pyrene based on total number of animals with tumours in mice treated with coal tar mixtures) rather than the intake estimate. It is difficult to compare approaches used for benzo(a)pyrene, however, as the present calculations were based on hepatocellular tumours in rats whereas the JECFA BMDL10 was derived from data for tumour-bearing animals in a mouse bioassay (Culp et al., 1998) where benzo(a)pyrene was used as a marker for mixtures of PAH in coal tar. While, responses based on tumour-bearing animals may be used, the toxicological points of departure used herein were based on single-tumour endpoints corrected for background. These comparisons emphasise that the MOE depends critically on the data selected and that a clear descriptive narrative of the method of estimation and associated assumptions and uncertainties is an essential part of the advice to risk managers.

\section{Data quality and data analysis considerations}

Whatever approach is chosen, the formulation of quantitative or semi-quantitative advice for risk managers places higher demands on raw data quality and on the methods used to analyse the data. Ideally, bioassay data should be from GLP studies using standard protocols. In addition, pathology peer review is increasingly being applied to the quality assurance of bioassay data. The details of methodology used to calculate food intakes should be provided. Assumptions and uncertainties in the calculation of food intake data should normally be communicated and data for average, or preferably median, and high consumers should be provided.

The T25 approach can be applied as soon as one dose shows a statistical difference from the control data, whereas the BMDL10 approach becomes more powerful as more responding groups are added. The closer the critical dose in the bioassay data is to the T25, the more accurate will be the T25 calculation. However, linear extrapolation may not reflect the true shape of the doseresponse curve, which mathematical dose-response models try to simulate in the calculation of the BMD and BMDL. When dose-response data are abundant, mathematical dose-response modelling can pool available dose-response data 
into a single best-fit. Under such circumstances, data obtained from this approach may be closer to 'true' values if good input data are available. However, the BMD/BMDL values obtained may be sensitive to the models used. Additional advantages of the modelling approach is the opportunity to estimate a lower bound value (the BMDL) which takes the variability in the data into account and the possibility to combine data from different sources (e.g. different sexes or different studies), provided this is biologically justifiable.

The shape of the dose-response curve will determine the relationship between the T25 and the BMD10/BMDL10. If the dose-response is linear, it would be expected that the T25 would be 2.5 times the BMD10 (a 25\% incidence versus a $10 \%$ incidence). Under such circumstances, the difference between the T25 and BMDL10 would be expected to be even greater, perhaps as much as fivefold, assuming that noise accounts for a twofold variation in most data sets. The ratio between the values for T25 and BMDL10 for the examples chosen here is much smaller than 5 . This observation suggests that when a T25 is used as a point of departure, it is unlikely to lead to an underestimation of risk, based on comparison with the BMD modelling approach.

\section{Conclusions}

The Expert Group concluded that each approach for the formulation of advice to risk managers is associated with strengths and weaknesses.

(i) ALARA - does not take into account either potency or exposure and is based on hazard identification alone. As such, the same advice is given irrespective of the potential risk. While ALARA is broadly applicable to genotoxic carcinogens in food, it is not recommended as the only form of advice to risk managers.

(ii) TTC - may be useful in circumstances where adequate cancer bioassay data are not available on a food contaminant known to be a direct-acting genotoxicant. Although still valid, in practice, the TTC approach would not be used when good hazard characterisation data are available.

(iii) Low-dose extrapolation takes into account both animal potency and human exposure in order to quantify the theoretical risk. The numerical estimate of risk is heavily influenced by the mathematical model selected for the extrapolation. On the other hand, the mathematical model chosen to derive a point of departure (such as a BMDL10 or T25) has little influence on the numerical estimate. Linear extrapolation from a point of departure has become a commonly used method, primarily for risk management considerations because it is often assumed that this will result in an upper bound of risk. However, linear extrapolation over many orders of magnitude does not reflect the underlying biological processes or the potential for significant non-linearity in the intake-response relationship outside the observed range. Linear extrapolation from the T25 or BMD10 to a $10^{-6}$ risk is simply equivalent to dividing the T25 by 250,000 and the BMD10 by 100,000 . This approach is therefore not recommended.

(iv) Overall, the MOE is the most appropriate default approach because it combines information on potency and exposure, without the generation of numerical risk estimates of unknown reliability. Table 1 showed that both the T25 and BMD approaches could be used as reference points on the intake response relationship to calculate MOEs for the comparison of the food-borne carcinogens selected. 
(v) Although the MOE is easy to calculate, the interpretation of any given MOE is complex and would have to take into account the nature and quality of both the tumourigenicity data and the exposure estimates (in reality these considerations apply equally to any method used). Equivalent data quality and data analysis methodology are necessary to ensure meaningful comparison of MOEs from different studies.

(vi) Further work is necessary to harmonise the estimation of food chemical intakes and to examine the range and significance of MOEs of genotoxic carcinogens commonly found in the human diet under different conditions of exposure.

\section{Supplementary data}

Supplementary documentation on DNA damage, repair and mutation prepared by the Expert Group may be downloaded from

http://europe.ilsi.org/taskforces/riskassessment/RiskAssessmentCarcinogens.htm

\section{Acknowledgements}

This document was prepared by an expert group commissioned by the Risk Assessment of Genotoxic Carcinogens in Food Task Force of the European Branch of the International Life Sciences Institute (ILSI Europe). Industry members of this task force are Coca-Cola, Firmenich, Givaudan, Groupe Danone, Nestlé, Procter \& Gamble and Unilever. The opinions expressed herein are those of the authors and do not necessarily represent the views of their employers or of ILSI and ILSI Europe.

The authors would like to thank Penelope Fenner-Crisp (formerly ILSI Risk Science Institute) and Barry Elliott (Syngenta Ltd.) for their valuable contribution to the work of the expert group as well as Lutz Edler (German Cancer Research Centre) and Diane Benford (Food Standards Agency, UK) for their helpful comments on the manuscript.

\section{References}

Akaike, $1974 \mathrm{H}$. Akaike, A new look at the statistical model identification, IEEE Transactions on Automatic Control 19 (1974), pp. 716-723.

Ames and Gold, 1991 B.N. Ames and L.S. Gold, Cancer prevention strategies greatly exaggerate risks, Chemical and Engineering News 1 (1991), pp. 28-32.

Andersen, 2003 M.E. Andersen, Toxicokinetic modeling and its applications in chemical risk assessment, Toxicology Letters 138 (2003), pp. 9-27.

Balmain, 2002 A. Balmain, Cancer as a complex genetic trait: tumor susceptibility in humans and mouse models, Cell 108 (2002), pp. 145-152. 
Barlow et al., 2002a S. Barlow, E. Dybing, L. Edler, G. Eisenbrand, R. Kroes and P. van den Brandt, Food safety in Europe (FOSIE): risk assessment of chemical in food and diet, Food and Chemical Toxicology 2/3 (2002), pp. 141-427.

Barlow et al., 2002b S.M. Barlow, J.B. Grieg, J.W. Bridges, A. Carere, A.J.M. Carpy, C.L. Galli, J. Kleiner, I. Knudsen, H.B.W.M. Koeter, L.S. Levy, C. Madsen, S. Mayer, J.-F. Narbonne, F. Pfannbuch, M.G. Prodanchuk, M.R. Smith and P. Steinberg, Hazard identification by methods of animal-based toxicology, Food and Chemical Toxicology 40 (2002) (2/3), pp. 145-191.

Barlow et al., 2006 Barlow, S., Renwick, A.G., Kleiner, J., Bridges, J., Busk, L., Dybing, E., Edler, L., Eisenbrand, G., Fink-Gremmels, J., Knaap, A. Kroes R., Liem, D. Müller, D.J.G., Page, S., Rolland, V., Schlatter, J., Tritscher, A., Tueting, W., Würtzen, G., 2006. Risk assessment of substances that are both genotoxic and carcinogenic. Report of an international conference. Food and Chemical Toxicology, in press, doi:10.1016/j.fct.2006.06.020.

Bozdogan, $1987 \mathrm{H}$. Bozdogan, Model selection and Akaike's information criterion (AIC): the general theory and its analytical extensions, Psychometrika 52 (1987), pp. 345-370.

Brusick, 2001 D. Brusick, Genetic toxicology. In: A. Wallace Hayes, Editor, Principles and Methods of Toxicology (fourth ed.), Taylor \& Francis, Philadelphia (2001), pp. 819-852.

Committee on Mutagenicity, 2000 Committee on Mutagenicity of Chemicals in Food, Consumer Products and the Environment, 2000. Guidance on a Strategy for Testing of Chemicals for Mutagenicity. Department of Health, London.

Crebelli, 2000 R. Crebelli, Threshold-mediated mechanisms in mutagenesis: implications in the classification and regulation of chemical mutagens, Mutation Research 464 (2000), pp. 129-135.

Culp et al., 1998 S.J. Culp, D.W. Gaylor, W.G. Sheldon, L.S. Goldstein and F.A. Beland, A comparison of the tumors induced by coal tar and benzo(a)pyrene in a 2-year bioassay, Carcinogenesis 19 (1998), pp. 117-124.

D'Errico et al., 1999 A. D'Errico, N. Malats, P. Vineis and P. Boffetta, Review of studies of selected metabolic polymorphisms and cancer, IARC Scientific Publications 148 (1999), pp. 323-393.

Dorne et al., 2005 J.L.C.M. Dorne, K. Walton and A.G. Renwick, Human variability in xenobiotic metabolism and pathway-related uncertainty factors for chemical risk assessment: a review, Food and Chemical Toxicology 43 (2005), pp. 203216.

Douglass and Tennant, 1997 J.S. Douglass and D.R. Tennant, Estimation of dietary intake of food chemicals. In: D.R. Tennant, Editor, Food Chemical Risk Analysis, Blackie Academic and Professional, Chapman and Hall, London (1997), pp. 195-218.

Dybing et al., 2002 E. Dybing, J. Doe, J. Groten, J. Kleiner, J. O'Brien, A.G. Renwick, J. Schlatter, P. Steinberg, A. Tritscher, R. Walker and M. Younes, Hazard characterization of chemicals in food and diet: dose response, mechanisms and extrapolation issues, Food and Chemical Toxicology 40 (2002), pp. 237-282. 
Dybing et al., 1997 E. Dybing, T. Sanner, H. Roelfzema, D. Kroese and R.W. Tennant, T25: a simplified carcinogenic potency index: Description of the system and study of correlations between carcinogenic potency and species/site specificity and mutagenicity, Pharmacology and Toxicology 80 (1997), pp. 272279.

Dybing and Sanner, 2003 E. Dybing and T. Sanner, Risk assessment of acrylamide in foods, Toxicological Sciences 75 (2003), pp. 7-15.

Edler et al., 2002 L. Edler, K. Poirer, M. Dourson, J. Kleiner, B. Mileson, H. Nordmann, A. Renwick, W. Slob, K. Walton and A. Visconti, Mathematical modeling and quantitative methods, Food and Chemical Toxicology 40 (2002), pp. 327-385.

European Commission, 2000 European Commission, 2000. Report of the EC Scientific Steering Committee's Working Group on Harmonisation of Risk Assessment Procedures in the Scientific Committees advising the European Commission in the area of human and environmental health-27-27 October 2000. Part 2. Appendix I- Glossary of terms. Available from: <http://europa.eu.int/comm/food/fs/sc/ssc/out82_en.html>.

EFSA, 2005 European Food Safety Authority 2005. Opinion of the Scientific Committee on a request from EFSA related to a harmonised approach for risk assessment of substances which are both genotoxic and carcinogenic. Request No EFSA-Q-2004-020. Adopted on 18 October 2005. Available from: <http://www.efsa.eu.int/science/sc_commitee/sc_opinions/1201_en.html>.

Gaylor and Gold, 1998 D.W. Gaylor and L.S. Gold, Regulatory cancer risk assessment based on a quick estimate of a benchmark dose derived from the maximum tolerated dose, Regulatory Toxicology and Pharmacology 28 (1998), pp. 222-225.

Gaylor, 2000 D.W. Gaylor, New issues in cancer risk assessment, Drug Metabolism Reviews 32 (2000), pp. 187-192.

Gold et al., 1999 L.S. Gold, N.B. Manley, T.H. Slone and L. Rohrbach, Supplement to the carcinogenic potency database (CPDB): results of animal bioassays published in the general literature in 1993 to 1994 and by the National Toxicology Program in 1995 to 1996, Environmental Health Perspectives 107 (1999) (4), pp. 3-123.

Hanahan and Weinberg, 2000 D. Hanahan and R.A. Weinberg, The hallmarks of cancer, Cell 100 (2000), pp. 57-70.

Hasegawa et al., 1993 R. Hasegawa, M. Sano, S. Tamano, K. Imaida, T. Shirai, M. Nagao, T. Sugimura and N. Ito, Dose dependence of 2-amino-1-methyl-6phenylimidazo[4,5-b]pyridine (PhIP) carcinogenicity in rats, Carcinogenesis 14 (1993), pp. 2553-2557.

Health Canada, 1994 Health Canada 1994. Human Health Risk Assessment for Priority Substances. Environmental Health Directorate, Health Canada, Canada Communication Group-Publishing, Cat No En40-215/41E, Ottawa, 1994.

Henderson et al., 2000 L. Henderson, S. Albertini and M. Aardema, Thresholds in genotoxicity responses, Mutation Research 464 (2000), pp. 123-128. 
Hoeijmakers and Bootsma, 1990 J.H.J. Hoeijmakers and D. Bootsma, Molecular genetics of eukaryotic DNA excision repair, Cancer Cells 2 (1990), pp. 311-319.

Jeffrey and Williams, 2005 A.M. Jeffrey and G.M. Williams, Risk assessment of DNA-reactive carcinogens in food. Proceedings 10th International Congress of Toxicology, Toxicology and Applied Pharmacology 207 (2005), pp. 628-635.

Johnson et al., 1986 K.A. Johnson, S.J. Gorzinski, K.M. Bodner, R.A. Bampbell, C.HI. Wolf, M.A. Friedman and R.W. Mast, Chronic toxicity and oncogenicity study on acrylamide incorporated in the drinking water of Fischer 344 rats, Toxicology and Applied Pharmacology 85 (1986), pp. 154-168.

JECFA, 1998 Joint FAO/WHO Expert Committee on Food Additives 1998. JECFA Safety evaluations of certain food additives and contaminants. Aflatoxins. WHO Food Additives Series 40. World Health Organization, Geneva, pp. 359-468.

JECFA, 2005 Joint FAO/WHO Expert Committee on Food Additives 2005. JECFA Sixty-fourth Meeting, Rome, 8-17 February 2005. Summary and Conclusions. FAO/WHO. Available from:

<ftp://ftp.fao.org/es/esn/jecfa/jecfa64_summary.pdf >.

Kirkland and Müller, 2000 D.J. Kirkland and L. Müller, Interpretation of the biological relevance of genotoxicity test results: the importance of thresholds, Mutation Research 464 (2000), pp. 137-147.

Kroes et al., 2002 R. Kroes, D. Muller, J. Lambe, M.R.H. Lowik, J. van Klaveren, J. Kleiner, R. Massey, S. Mayer, I. Urieta, P. Verger and A. Visconti, Assessment of intake from the diet, Food and Chemical Toxicology 40 (2002) (2/3), pp. 327385.

Kroes et al., 2004 R. Kroes, A.G. Renwick, M. Cheeseman, J. Kleiner, I. Mangelsdorf, A. Piersma, B. Schilter, J. Schlatter, F. van Schothorst, J.G. Vos and G. Würtzen, Structure-based thresholds of toxicological concern (TTC): guidance for application to substances present at low levels in the diet, Food and Chemical Toxicology 42 (2004), pp. 65-83.

Kroese et al., 2001 Kroese, E.D., Muller, J.J.A., Mohn, G.R., Dortant, P.M., Wester, P.W., 2001. Tumorigenic effects in Wistar rats orally administered benzo[a]pyrene for two years (gavage studies). Implications for human cancer risks associated with oral exposure to polycyclic aromatic hydrocarbons. RIVM, Bilthoven, Report No. 658603010.

Lewis et al., 2002 S.J. Lewis, N.M. Cherry, R.M. Niven, P.V. Barber and A.C. Povey, GSTM1, GSTT1 and GSTP1 polymorphisms and lung cancer risk, Cancer Letters 180 (2002), pp. 165-171.

Lutz and Schlatter, 1992 W.K. Lutz and J. Schlatter, Chemical carcinogens and overnutrition in diet-related cancer, Carcinogenesis 13 (1992), pp. 2211-2216.

MacDonald et al., 2001 MacDonald, J, Robinson, D.E., Pettit, S., (Eds.), 2001. An evaluation of alternative methods for carcinogenicity testing. Toxicologic Pathology 29, (Supplement 1). 
Moerbeek et al., 2003 M. Moerbeek, A.H. Piersma and W. Slob, A comparison of three methods for calculating confidence intervals for the benchmark dose, Risk Analysis 24 (2003), pp. 31-40.

Mohrenweiser, 2004 H.W. Mohrenweiser, Genetic variation and exposure related risk estimation: will toxicology enter a new era? DNA repair and cancer as a paradigm, Toxicologic Pathology 32 (2004), pp. 136-145.

Moolgavkar and Luebeck, 1990 S.H. Moolgavkar and G. Luebeck, Two-event model for carcinogenesis: biological, mathematical, and statistical considerations, Risk Analysis 10 (1990), pp. 323-341.

Müller and Kasper, 2000 L. Müller and P. Kasper, Human biological relevance and the use of threshold-arguments in regulatory genotoxicity assessment: experience with pharmaceuticals, Mutation Research 464 (2000), pp. 19-34.

Myrnes et al., 1983 B. Myrnes, K.E. Giercksky and H. Krokan, Interindividual variation in the activity of $\mathrm{O}^{6}$-methyl guanine-DNA methyltransferase and uracilDNA glycosylase in human organs, Carcinogenesis 4 (1983), pp. 1565-1568.

National Cancer Institute, 1979 National Cancer Institute 1979. Perinatal Carcinogenesis. NCI Monograph 51. DHEW Publication No. (NIH) 79-1633.

Nebert et al., 1996 D.W. Nebert, R.A. McKinnon and A. Puga, Human drugmetabolizing enzyme polymorphisms: effects on risk of toxicity and cancer, DNA and Cell Biology 15 (1996), pp. 273-280.

Oesch et al., 2000 F. Oesch, M.E. Herrero, J.G. Hengstler, M. Lohmann and M. Arand, Metabolic detoxification: implications for thresholds, Toxicologic Pathology 28 (2000), pp. 382-387.

Petersen, 2002 B. Petersen, Estimating dietary exposure: methods, algorithms and general considerations. In: D. Paustenback, Editor, Human and Ecological Risk Assessment: Theory and Practice, Wiley Interscience, New York (2002), pp. 895-912.

Peto et al., 1991a R. Peto, R. Gray, P. Brantom and P. Grasso, Effects on 4080 rats of chronic ingestion of $N$-nitrosodiethylamine or $N$-nitrosodimethylamine: a detailed dose-response study, Cancer Research 51 (1991), pp. 6415-6451.

Peto et al., 1991b R. Peto, R. Gray, P. Brantom and P. Grasso, Dose and time relationships for tumor induction in the liver and esophagus of 4080 inbred rats by chronic ingestion of $N$-nitrosodiethylamine or $N$-nitrosodimethylamine, Cancer Research 51 (1991), pp. 6452-6469.

Peto et al., 1984 R. Peto, M.C. Pike, L. Bernstein, L.S. Gold and B.N. Ames, The TD-50: a proposed general convention for the numerical description of the carcinogenic potency of chemicals in chronic-exposure animal experiments, Environmental Health Perspectives 58 (1984), pp. 1-8.

Preston and Williams, 2005 R.J. Preston and G.M. Williams, DNA-reactive carcinogens: mode of action and human cancer hazard, CRC Reviews in Toxicology 35 (2005), pp. 1-11. 
Renwick, 2001 A.G. Renwick, Toxicokinetics: pharmacokinetics in toxicology. In: A.W. Hayes, Editor, Principles and Methods of Toxicology, Taylor \& Francis, Philadelphia (2001), pp. 137-191.

Renwick et al., 2003 A.G. Renwick, S. Barlow, I. Hertz-Picciotto, A.R. Boobis, E. Dybing, L. Edler, G. Eisenbrand, J.B. Grieg, J. Kleiner, J. Lambe, D.J.G. Muller, M.R. Smith, A. Tritscher, S. Tuijelaars, P.A. van den Brandt, R. Walker and R. Kroes, Risk characterisation of chemicals in food and diet, Food and Chemical Toxicology 41 (2003), pp. 1211-1271.

Sanner et al., 2001 T. Sanner, E. Dybing, M.I. Willems and E.D. Kroese, A simple method for quantitative risk assessment of non-threshold carcinogens based on the dose descriptor T25, Pharmacology \& Toxicology 88 (2001), pp. 331-341.

SCF, 1996 Scientific Committee for Food 1996. The scientific basis of the concept of threshold of regulation in relation to food contact materials (Opinion expressed on 8 March 1996). Available from:

<http://europa.eu.int/comm/food/fs/sc/scf/reports/scf_reports_39.pdf>.

Slob et al., 2006 W. Slob, Probabilistic dietary exposure assessment taking into account variability in both amount and frequency of consumption, Food and Chemical Toxicology 44 (2006), pp. 933-951.

Swenberg et al., 1995 J.A. Swenberg, D.K. La, N.A. Scheller and K.Y. Wu, Doseresponse relationships for carcinogens, Toxicology Letters 82-83 (1995), pp. 751-756.

Swenberg et al., 2000 J.A. Swenberg, A. Ham, H. Koc, E. Morinello, A. Ranasinghe, N. Tretyakova, P.B. Upton and K.-Y. Wu, DNA adducts: effects of low exposure to ethylene oxide, vinylchloride and butadiene, Mutation Research 464 (2000), pp. 77-86.

Tong et al., 1980 C. Tong, M. Fazio and G.M. Williams, Cell cycle-specific mutagenesis at the hypoxanthine phosphoribosyl-transferase locus in adult rat liver epithelial cells, Proceedings of the National Academy of Sciences USA 77 (1980), pp. 7377-7379.

US Environmental Protection Agency, 2000 US Environmental Protection Agency, 2000. Science Policy Council Handbook: Risk Characterization. EPA 100-B-00002. US Environmental Protection Agency, Washington, DC. Available from: <http://www.epa.gov/osp/spc/rchandbk.pdf>.

US FDA Redbook, 2000 US Food and Drug Administration Redbook, 2000. Toxicological Principles for the Safety Evaluation of Food Ingredients. Office of Food Additive Safety, FDA, Washington, DC. Available from: $<$ www.cfsan.fda.gov/ redbook/red-toca.html>.

US FDA, 2004 US Food and Drug Administration, 2004. Acrylamide in Food JIFSAN Workshop 2004. Available from:

$<$ http://www.jifsan.umd.edu/presentations/acry2004/acry_2004_dinovihoward.p df $>$.

US National Toxicology Program, 2002 US National Toxicology Program, 2002. NTP: Executive Working Group for the Report on Carcinogens - RG2, Review Date 
10/2/02. Available from: <http://ntp-

server.niehs.nih.gov/ntp/newhomeroc/roc11/HCA_RG2Summary-final.pdf>.

US NTP, 2004 US National Toxicology Program, 2004. NTP Technical Report on the Toxicology and Carcinogenesis Studies of Urethane, Ethanol, Urethane/Ethanol in B6C3F1 Mice (drinking water study). NTP Publication No 044444, US Department of Health and Human Services, Washington.

Vineis, 2004 P. Vineis, Individual susceptibility to carcinogens, Oncogene 23 (2004), pp. 6477-6483.

Williams, 1992 G.M. Williams, DNA reactive and epigenetic carcinogens, Experimental and Toxicological Pathology 44 (1992), pp. 457-564.

Williams, 1999 G.M. Williams, Chemically induced rodent preneoplastic lesions as indicators of carcinogenic activity. In: D.B. McGregor et al., Editors, The Use of Short- and Medium-Term Tests for Carcinogens and Data on Genetic Effects in Carcinogenic Hazard Evaluation, IARC Scientific Publications No. 146, IARC, Lyon (1999), pp. 185-202.

Williams and Iatropoulos, 2001 G.M. Williams and M.J. Iatropoulos, Principles of testing for carcinogenic activity. In: W. Hayes, Editor, Principles \& Methods of Toxicology (fourth ed.), Taylor \& Francis, Philadelphia (2001), pp. 959-1000.

Williams et al., 2000 G.M. Williams, M.J. Iatropoulos and A.M. Jeffrey, Mechanistic basis for nonlinearities and thresholds in rat liver carcinogenesis by the DNAreactive carcinogens 2-acetylaminofluorene and diethylnitrosamine, Toxicological Pathology 28 (2000), pp. 388-395.

Williams et al., 2005 G.M. Williams, A.M. Jeffrey and M.J. Iatropoulos, Thresholds for DNA-reactive (genotoxic) organic carcinogens, Journal of Toxicological Pathology 18 (2005), pp. 69-77.

Wogan et al., 1974 G.N. Wogan, S. Paglialunga and P.M. Newberne, Carcinogenic effects of low dietary levels of aflatoxins, Food and Cosmetics Toxicology 12 (1974), pp. 681-685.

WHO, 1974 World Health Organization, 1974. Assessment of the carcinogenicity and mutagenicity of chemicals: report of a WHO scientific group (meeting held in Geneva from 13 to 17 August, 1973). World Health Organisation, Geneva.

WHO, 1995 World Health Organization, 1995. WHO Report of a Workshop in the Frame of GEMS/Food-Euro, Kulmbach, Germany, 26-27 May 1995. Available from:

<http://www.who.int/foodsafety/publications/chem/lowlevel_may1995/en/index. html>.

WHO, 1998 World Health Organization, 1998. WHO Food Additives Series 40, World Health Organization, Geneva. Available from:

<http://www.inchem.org/documents/jecfa/jecmono/v040je16.htm>.

Woutersen et al., 2001 R.A. Woutersen, D. Jonker, H. Stevenson, J.D. te Biesebeek and W. Slob, The benchmark approach applied to a 28-day toxicity study with Rhodorsil Silane in rats: the impact of increasing the number of dose groups, Food and Chemical Toxicology 39 (2001), pp. 697-707. 
Zimmerli and Schlatter, 1991 B. Zimmerli and J. Schlatter, Ethylcarbamate: analytical methodology, occurrence, formation, biological activity and risk assessment, Mutation Research 259 (1991), pp. 325-350.

\section{Appendix A. Margins of exposure calculated from T25 and BMDL10 values for selected carcinogens and selected human exposure data ${ }^{5}$}

\section{A.1. Introduction}

Selected food-borne carcinogens were used to illustrate the calculation of margins of exposure. The food intake and rodent bioassay data were selected from published sources to illustrate the margin of exposure approach and were not quality assured. Non-food exposures were not evaluated. The compounds selected were: acrylamide, aflatoxin $\mathrm{B}_{1}$, benzo(a)pyrene, ethyl carbamate, and PhIP (2-amino-1-methyl-6-phenylimidazo[4,5-b]pyridine).

Calculations of T25, BMD10 and BMDL10 values were based on selected single tumour data (for biologically significant tumours) in animals administered the test compound for a period of 104 weeks (referred to herein as the critical endpoint).

The T25 value is the chronic daily dose, which will give tumours in $25 \%$ of the animals above background at a specific tissue site. The T25 is determined by linear extrapolation from the lowest dose giving a statistically significant increase in tumours (referred to herein as the critical dose) (Dybing et al., 1997). The calculation of T25 values is derived from the following data:

A: proportion of animals with the tumour in the control group (\%)

B: proportion of animals with the tumour in an exposed group (\%)

C: net increase in tumour frequency (\%)

$$
\begin{aligned}
& C=[(B / 100-A / 100) /(1-A / 100)] \times 100 \\
& \mathrm{~T} 25=(25 / C) \times \text { critical dose }
\end{aligned}
$$

Values for the BMD10 and BMDL10 were calculated from the same animal doseresponse data following fitting to a set of mathematical models that comprised one-stage model, two-stage model, three-stage model, log-logistic model, Weibull model, log-probit model, Hill model, and four latent variable models (denoted as PROAST M2, PROAST M3, PROAST M4, and PROAST M5; see Woutersen et al., 2001). The number of parameters in these models varies from 2 (one-stage model) up to 4 (Hill model and PROAST M5). The Hill model, and PROAST models M4 and M5 have the potential to level off below $100 \%$ at increasing doses.

The acceptability of a model was based on the criterion that the fit should not be significantly worse (using the likelihood ratio test) than the fit provided by the saturated model. The saturated model is the model that does not assume any dose-response function (its parameters are simply the frequencies per dose level). Some of the models are nested models (i.e. they are related to each other such that by leaving out a parameter, one model reduces to the other; this holds for the one, two, and three-stage models, as well as for the PROAST models). These nested models were also compared to each other (by the likelihood ratio 
test), and a model with more parameters was only accepted if it fitted significantly better than its counterpart with less parameters.

While the likelihood ratio test can only be applied to nested models, the AIC criterion (Akaike, 1974 and Bozdogan, 1987) has been proposed as an approximate criterion for comparing the fits of non-nested models. However, applying the AIC approach may lead to more models being excluded, in many cases leaving just one model. It was preferred therefore to omit this criterion and to report the $\mathrm{BMD}(\mathrm{L}) \mathrm{s}$ for the other models as well. This gives some indication of the "model uncertainty" (i.e. the uncertainty regarding the true shape of the dose-response) in each data set. When the data are relatively sparse (e.g. few dose groups) this uncertainty in the data will be relatively large. The confidence intervals were calculated by the profile likelihood method, except for the PROAST models, where they were assessed by bootstrapping (see Moerbeek et al., 2003). The lowest value of the BMDL10 was chosen in each case for the calculation of the MOE.

In the case of benzo(a)pyrene and ethyl carbamate the models were fitted to the results for both sexes combined. By having sex as a covariate for one of the model parameters, the likelihood ratio test can be used to decide if both sexes differ in the value of a particular parameter, or that both sexes can just as well be considered as one single population.

The PROAST software was used, but the US-EPA benchmark dose software (BMDS) should give the same results for the supported models. However, the Hill model, and the PROAST models are not implemented in BMDS. The BMD software can be downloaded from http://epa.gov/ncea/bmds.htm. This software is quick to learn and apply. The PROAST software is available on request from RIVM, but requires SPLUS (a commercial software package) or $\mathrm{R}$ (freeware).

\section{A.2. Acrylamide}

\section{A.2.1. Human exposure data}

For acrylamide, published human exposure estimates from Norway and USA were used for the MOE calculations in Table 2. In Norway, mean exposure was estimated to be 410 and $420 \mathrm{ng} / \mathrm{kg}$ bw/d for males and females, respectively (Dybing and Sanner, 2003). In the USA, the mean exposure was estimated to be $430 \mathrm{ng} / \mathrm{kg} \mathrm{bw} / \mathrm{d}$ and the 90 th percentile was $920 \mathrm{ng} / \mathrm{kg} \mathrm{bw} / \mathrm{d}$ (US FDA, 2004). Some population sub-groups may have higher exposures that are difficult to evaluate. For example, one survey reported a value of $2.31 \mu \mathrm{g} / \mathrm{kg} \mathrm{bw} / \mathrm{d}$ for a $90 \mathrm{th}$ percentile exposure for children aged 2-5 years (US FDA, 2004).

Table 2.

Acrylamide bioassay data: tumour incidences observed in rats

\begin{tabular}{|l|l|l|l|l|l|}
\hline & \multicolumn{5}{|l|}{ Dose (mg/kg bw/day) } \\
\hline & $\mathbf{0}$ & $\mathbf{0 . 0 1}$ & $\mathbf{0 . 1}$ & $\mathbf{0 . 5}$ & $\mathbf{2 . 0}$ \\
\hline Males & $1 / 60$ & $0 / 58$ & $2 / 59$ & $1 / 59$ & $7 / 59$ \\
\hline Thyroid adenomas & $3 / 60$ & $0 / 60$ & $7 / 60$ & $11 / 60$ & $10 / 60$ \\
\hline Testicular mesotheliomas &
\end{tabular}




\begin{tabular}{|l|l|l|l|l|l|}
\hline & \multicolumn{5}{|l}{ Dose (mg/kg bw/day) } \\
\hline & $\mathbf{0}$ & $\mathbf{0 . 0 1}$ & $\mathbf{0 . 1}$ & $\mathbf{0 . 5}$ & $\mathbf{2 . 0}$ \\
\hline Adrenal pheochromocytomas & $3 / 60$ & $7 / 59$ & $7 / 60$ & $5 / 60$ & $10 / 60$ \\
\hline & & & & & \\
\hline Females & & & & & \\
\hline Thyroid adenomas & $0 / 58$ & $0 / 59$ & $1 / 59$ & $1 / 58$ & $3 / 60$ \\
\hline Thyroid adenocarcinomas & $1 / 58$ & $0 / 59$ & $0 / 59$ & $0 / 58$ & $3 / 60$ \\
\hline Mammary gland fibroadenomas & $10 / 60$ & $11 / 60$ & $9 / 60$ & $19 / 58$ & $23 / 61$ \\
\hline Mammary gland adenocarcinomas & $2 / 60$ & $1 / 6$ & $1 / 60$ & $2 / 58$ & $6 / 61$ \\
\hline Uterine adenocarcinomas & $1 / 60$ & $2 / 60$ & $1 / 60$ & $0 / 59$ & $5 / 60$ \\
\hline Oral cavity papillomas & $0 / 60$ & $3 / 60$ & $2 / 60$ & $1 / 60$ & $7 / 60$ \\
\hline
\end{tabular}

\section{A.2.2. Bioassay data}

Groups of 60 male and 60 female Fischer 344 rats were given acrylamide in drinking water at levels corresponding to doses of $0,0.01,0.1,0.5$ and $2.0 \mathrm{mg} / \mathrm{kg} \mathrm{bw} / \mathrm{d}$ (Johnson et al., 1986). The tumour incidences observed in the rats are listed in Table 2.

\section{A.2.3. Calculation of T25 values}

\section{Remarks on study}

Species, strain, sex Rat, Fischer 344, female

Route Oral, drinking water

Critical endpoint Mammary gland fibroadenomas

Critical dose $\quad 0.5 \mathrm{mg} / \mathrm{kg} \mathrm{bw} / \mathrm{d}$

Duration 104 weeks (default)

Lowest dose with a significantly increased tumour incidence

Control

$10 / 60(16.7 \%)$

Dose $0.5 \mathrm{mg} / \mathrm{kg} \mathrm{bw} / \mathrm{d}$

$19 / 58(32.8 \%)$

Net increase

$[(32.8 / 100-16.7 / 100) /(1-16.7 / 100)] \times 100=19.3 \%$

T25 calculation: 


$$
\mathrm{T} 25=25 / 19.3 \times 0.5 \mathrm{mg} / \mathrm{kg} \mathrm{bw} / \mathrm{d}=0.65 \mathrm{ng} / \mathrm{kg} \mathrm{bw} / \mathrm{d}
$$

\section{A.2.4. Calculation of BMDL10 values}

Table 3 shows the BMD calculations as modelled on mammary gland fibroadenomas (Johnson et al., 1986). The lowest BMDL10 value is $0.31 \mathrm{mg} / \mathrm{kg}$ bw/d.

-Table 3.

Acrylamide: BMD modelling on mammary gland fibroadenomas (Johnson et al., 1986)

\begin{tabular}{|l|l|l|l|l|l|}
\hline Model & npar & loglik & Accepted & $\begin{array}{l}\text { BMD10 (mg/kg } \\
\text { bw/d) }\end{array}$ & $\begin{array}{l}\text { BMDL10 (mg/kg } \\
\text { bw/d) }\end{array}$ \\
\hline Saturated model & 5 & -158.08 & & & \\
\hline One-stage model & 2 & -159.65 & Yes & 0.65 & 0.40 \\
\hline Two-stage model & 3 & -159.65 & No $^{c}$ & & \\
\hline Log-logistic model $^{\mathrm{b}}$ & 3 & -159.48 & Yes & 0.56 & 0.31 \\
\hline Weibull model & 3 & -159.65 & Yes & 0.65 & 0.40 \\
\hline Proast M2 & 2 & -160.01 & Yes & 0.86 & $0.62^{\mathrm{a}}$ \\
\hline
\end{tabular}

${ }^{a}$ Based on 500 bootstrap runs.

${ }^{b}$ Fitted with constraint to prevent supralinearity.

${ }^{c}$ Because no significant improvement in model fit was seen over the one-stage model.

\section{A.3. Aflatoxin $B_{1}$}

\section{A.3.1. Human exposure data}

For aflatoxin $B_{1}$, human exposure estimates from a monograph prepared by the Joint FAO/WHO Expert Committee on Food Additives (JECFA) were used (WHO, 1998). If foods are consumed according to the "European diet" (www.who.int/foodsafety/chem/gems/en/index.html) with a relatively low contamination level in food and where all samples with contamination above $20 \mu \mathrm{g} / \mathrm{kg}$ product were removed, the mean estimated intake of aflatoxin was $19 \mathrm{ng} /$ person per day ( $\sim 0.3 \mathrm{ng} / \mathrm{kg} \mathrm{bw} / \mathrm{d}$ ). This fits well with national data from Switzerland $(0.25 \mathrm{ng} / \mathrm{kg}$ bw/d, Lutz and Schlatter, 1992). If foods are consumed according to the "Far Eastern Diet"

(www.who.int/foodsafety/chem/gems/en/index.html) with higher contamination levels in food (e.g. using monitoring data from China) but also removing all samples with contamination above $20 \mu \mathrm{g} / \mathrm{kg}$ product, the mean estimated intake of aflatoxin was $125 \mathrm{ng} /$ person per day $(\approx 2.0 \mathrm{ng} / \mathrm{kg} \mathrm{bw} / \mathrm{d})$.

\section{A.3.2. Bioassay data}

Groups of male Fischer rats (initial number unspecified) were fed a diet containing $0,1,5,15,50$ or $100 \mu \mathrm{g}$ aflatoxin $B_{1} / \mathrm{kg}$ of diet until clinical deterioration of 
animals was observed, at which time all survivors in that treatment group were killed (Wogan et al., 1974). The following incidences of hepatocellular carcinomas were observed: $0 / 18$ (control), $2 / 22(1 \mu \mathrm{g} / \mathrm{kg}$ of diet), $1 / 22(5 \mu \mathrm{g} / \mathrm{kg}$ of diet), $4 / 21(15 \mu \mathrm{g} / \mathrm{kg}$ of diet), 20/25 (50 $\mathrm{gg} / \mathrm{kg}$ of diet) and $28 / 28(100 \mu \mathrm{g} / \mathrm{kg}$ of diet). These feed concentrations corresponded to doses of $0.05,0.1,0.3,2$ and $4 \mu \mathrm{g} / \mathrm{kg}$ bw/d, respectively (assuming default body weight male rats $500 \mathrm{~g}$ and default feed consumption male rats $20 \mathrm{~g} / \mathrm{d} ; 50 \mu \mathrm{g} / \mathrm{kg}$ of diet corresponds to a dose of $(50 \mu \mathrm{g} / \mathrm{kg} \times 0.02 \mathrm{~kg}$ feed $/ \mathrm{d}) / 0.5 \mathrm{~kg} \mathrm{bw}=2 \mu \mathrm{g} / \mathrm{kg} \mathrm{bw} / \mathrm{d})$.

\title{
A.3.3. Calculation of $\mathrm{T} 25$ values
}

\author{
Remarks on study \\ Species, strain, sex Rat, Fischer, male \\ Route Oral, feed \\ Critical endpoint Hepatocellular carcinoma \\ Critical dose $\quad 50 \mu \mathrm{g} / \mathrm{kg}$ of diet $=2 \mu \mathrm{g} / \mathrm{kg} \mathrm{bw} / \mathrm{d}$ \\ Duration 82 weeks for $50 \mu \mathrm{g} / \mathrm{kg}$ feed dose group
}

Daily dose if exposure was for 104 weeks:

$$
2 \mu \mathrm{g} / \mathrm{kg} \mathrm{bw} / \mathrm{d} \times 82 / 104=1.6 \mu \mathrm{g} / \mathrm{kg} \text { bw } / \mathrm{d}
$$

Lowest dose with a significantly increased tumour incidence

Control

$0 / 18(0 \%)$

Dose $1.6 \mu \mathrm{g} / \mathrm{kg} \mathrm{bw} / \mathrm{d}$

$20 / 25(80.0 \%)$

Net increase

$80.0 \%$

T25 calculation:

$$
\mathrm{T} 25=25 / 80 \times 1.6 \mu \mathrm{g} / \mathrm{kg} \text { bw } / \mathrm{d}=0.50 \mu \mathrm{g} / \mathrm{kg} \mathrm{bw} / \mathrm{d}
$$

\section{A.3.4. Calculation of BMDL10 values}

Table 4 shows the BMD calculations as modelled on hepatocellular carcinoma in male rats (Wogan et al., 1974). The lowest BMDL10 value is $0.20 \mu \mathrm{g} / \mathrm{kg} \mathrm{bw} / \mathrm{d}$; correction for exposure duration: $0.20 \times 82 / 104=0.16 \mu \mathrm{g} / \mathrm{kg} \mathrm{bw} / \mathrm{d}$. 
Table 4.

Aflatoxin $\mathrm{B}_{1}$ : BMD modelling on hepatocellular carcinoma in male rats (Wogan et al., 1974)

\begin{tabular}{|c|c|c|c|c|c|}
\hline Model & npar & loglik & Accepted & $\begin{array}{l}\text { BMD10 }(\mu \mathrm{g} / \mathrm{kg} \\
\mathrm{bw} / \mathrm{d})\end{array}$ & $\begin{array}{l}\text { BMDL10 }(\mu \mathrm{g} / \mathrm{kg} \\
\mathrm{bw} / \mathrm{d})\end{array}$ \\
\hline Saturated model & 6 & -33.52 & & & \\
\hline One-stage model & 2 & -38.45 & No & & \\
\hline Two-stage model & 3 & -34.85 & Yes & 0.48 & 0.20 \\
\hline Log-logistic model & 3 & -35.63 & Yes & 0.56 & 0.33 \\
\hline Weibull model & 3 & -34.86 & Yes & 0.51 & 0.26 \\
\hline Log-probit model & 3 & -35.32 & Yes & 0.56 & 0.34 \\
\hline Proast M2 & 2 & -34.82 & Yes & 0.50 & 0.38 \\
\hline
\end{tabular}

\section{A.4. Benzo(a)pyrene}

\section{A.4.1. Human exposure data}

Human exposure estimates for benzo(a)pyrene from food of $10-15 \mathrm{ng} / \mathrm{kg} \mathrm{bw} / \mathrm{d}$ was derived from the national data of Switzerland (Lutz and Schlatter, 1992).

\section{A.4.2. Bioassay data}

Groups of 52 male and 52 female Wistar strain rats were administered benzo(a)pyrene for 104 weeks at doses of $0,3,10$ and $30 \mathrm{mg} / \mathrm{kg}$ bw/d by gavage 5 days per week (Kroese et al., 2001). The following incidences of hepatocellular tumours were observed: male rats 0/52 (control), 4/52 (3 mg/kg bw/d), 38/52 $(10 \mathrm{mg} / \mathrm{kg} \mathrm{bw} / \mathrm{d})$ and $51 / 52(30 \mathrm{mg} / \mathrm{kg} \mathrm{bw} / \mathrm{d})$, female rats $0 / 50$ (control), 2/52 (3 mg/kg bw/d), 39/52 (10 mg/kg bw/d) and 51/52 (30 mg/kg bw/d).

\section{A.4.3. Calculation of $\mathrm{T} 25$ values}

\section{Remarks on study}

Species, strain, sex Rat, Wistar, female

Route Oral, gavage, 5 of 7 days per week

Critical endpoint Hepatocellular tumours

Critical dose $\quad 10 \mathrm{mg} / \mathrm{kg} \mathrm{bw} / \mathrm{d}$

Duration 104 weeks (default) 
Lowest dose with a significantly increased tumour incidence

Control

$0 / 52(0 \%)$

Dose $10 \mathrm{mg} / \mathrm{kg} \mathrm{bw} / \mathrm{d}$

$39 / 52(75.0 \%)$

Net increase

$75.0 \%$

T25 calculation:

$$
\begin{aligned}
\mathrm{T} 25 & =25 / 75.0 \times 10 \mathrm{mg} / \mathrm{kg} \text { bw } / \mathrm{d} \times 5 \text { days } / 7 \text { days } \\
& =2.4 \mathrm{mg} / \mathrm{kg} \text { bw } / \mathrm{d}
\end{aligned}
$$

\section{A.4.4. Calculation of BMDL10 values}

Table 5 shows the BMD calculations as modelled on hepatocellular tumours in rats of both sexes (Kroese et al., 2001). Dose-response analysis of the responses showed that there is no significant difference between the sexes. Therefore, both sexes were treated as a single population. The lowest BMDL10 value was $2.8 \mathrm{mg} / \mathrm{kg} \mathrm{bw} / \mathrm{d}$; correction for exposure duration: $2.8 \times 5$ days $/ 7$ days $=2.0 \mathrm{mg} / \mathrm{kg} \mathrm{bw} / \mathrm{d}$.

Table 5.

BaP: BMD modelling on hepatocellular tumours in rats (both sexes) (Kroese et al., 2001)

\begin{tabular}{|l|l|l|l|l|l|}
\hline Model & npar & loglik & Accepted & $\begin{array}{l}\text { BMD10 (mg/kg } \\
\text { bw/d) }\end{array}$ & $\begin{array}{l}\text { BMDL10 (mg/kg } \\
\text { bw/d) }\end{array}$ \\
\hline Saturated model & 4 & -92.38 & & & \\
\hline One-stage model & 2 & -110.98 & No & & \\
\hline Two-stage model & 3 & -103.29 & No & & \\
\hline Log-logistic model & 3 & -92.59 & Yes & 3.53 & 2.9 \\
\hline Weibull model & 3 & -100.49 & No & & \\
\hline Log-probit model & 3 & -93.32 & Yes & 3.36 & 2.8 \\
\hline Proast M4 & 3 & -92.77 & Yes & 4.05 & $3.5^{\mathrm{a}}$ \\
\hline
\end{tabular}

${ }^{\text {a }}$ Based on 500 bootstrap runs.

\section{A.5. Dimethylnitrosamine}

\section{A.5.1. Human exposure data}

A human exposure estimate for volatile nitrosamines from food of $14 \mathrm{ng} / \mathrm{kg} \mathrm{bw}$ was taken from Lutz and Schlatter (1992). This figure was derived from the national data of Switzerland and comprises both $N$-nitrosodimethylamine (dimethylnitrosamine) and $N$-nitrosopyrrolidine. 


\title{
A.5.2. Bioassay data
}

Groups of 60 male and 60 female inbred (Colworth Wistar) rats were given dimethylnitrosamine-containing drinking water until animals had palpable liver tumours or were dying ( 240 male and 240 female controls) (Peto et al., 1991a and Peto et al., 1991b). The calculated doses based on water consumption were as follows, males: $0,0.001,0.003,0.005,0.011,0.022,0.044,0.065,0.087$, $0.109,0.131,0.174,0.218,0.261,0.348$ and $0.697 \mathrm{mg} / \mathrm{kg} \mathrm{bw} / \mathrm{d}$ and females: 0 , $0.002,0.005,0.010,0.019,0.038,0.076,0.115,0.153,0.191,0.229,0.306$, $0.382,0.459,0.612$ and $1.224 \mathrm{mg} / \mathrm{kg} \mathrm{bw} / \mathrm{d}$. For the above doses, the following incidences of liver cell tumours were reported, respectively, in males: 10/240, $4 / 60,3 / 60,2 / 60,4 / 60,4 / 60,5 / 60,8 / 60,7 / 60,13 / 60,14 / 60,19 / 60,27 / 60$, $32 / 60,44 / 60$ and 46/60; and in females: $11 / 240,2 / 60,2 / 60,4 / 60,2 / 60,6 / 60$, $6 / 60,3 / 60,7 / 60,7 / 60,4 / 60,7 / 60,13 / 60,20 / 60,40 / 60$ and 41/60.

\section{A.5.3. Calculation of T25 values}

\author{
Remarks on study \\ Species, strain, sex Rat, Colworth Wistar, male \\ Route Oral, feed \\ Critical endpoint Liver cell tumours \\ Critical dose $\quad 0.109 \mathrm{mg} / \mathrm{kg} \mathrm{bw} / \mathrm{d}$ \\ Duration $\quad 104$ weeks for $0.109 \mathrm{mg} / \mathrm{kg} \mathrm{bw} / \mathrm{d}$ group
}

Lowest dose with a significantly increased tumour incidence

Control

$10 / 240(4.2 \%)$

Dose $0.109 \mathrm{mg} / \mathrm{kg} \mathrm{bw/d} 13 / 60(21.7 \%)$

Net increase $\quad[(21.7 / 100-4.2 / 100) /(1-4.2 / 100)] \times 100=18.3 \%$

T25 calculation:

$$
\mathrm{T} 25-25 / 18.3 \times 0.109 \mathrm{mg} / \mathrm{kg} \text { bw } / \mathrm{d}-0.15 \mathrm{mg} / \mathrm{kg} \text { bw } / \mathrm{d}
$$

\section{A.5.4. Calculation of BMDL10 values}

Table $6 \mathrm{a}$ and Table $6 \mathrm{~b}$ show the BMD calculations as modelled on liver cell tumours in male rats. The dose-response for liver cell tumours showed a sigmoidal dose-response, but at the top dose the response suddenly appears to level off (at an incidence level of around $70 \%$ ). This is probably due to interaction with the occurrence of other dose-related tumours. Therefore, dose-response analyses were performed both including (Table 6a) and excluding (Table 6b) the top dose, but this only marginally affected the BMDL10 values. For liver cell 
tumors (in males, top dose excluded) the lowest BMDL10 for dimethylnitrosamine is $0.062 \mathrm{mg} / \mathrm{kg} \mathrm{bw} / \mathrm{d}$.

Table 6a.

DMN: BMD modelling on liver cell tumours in males, top dose included

\begin{tabular}{|l|l|l|l|l|l|}
\hline Model & npar & loglik & Accepted & $\begin{array}{l}\text { BMD10 (mg/kg } \\
\text { bw/d) }\end{array}$ & $\begin{array}{l}\text { BMDL10 (mg/kg } \\
\text { bw/d) }\end{array}$ \\
\hline Saturated model & 16 & -420.27 & & & \\
\hline One-stage model & 2 & -429.24 & Yes & 0.046 & 0.041 \\
\hline Two-stage model & 3 & -428.94 & No & & \\
\hline Log-logistic model & 3 & -424.65 & Yes & 0.076 & 0.060 \\
\hline Weibull model & 3 & -427.68 & Yes & 0.061 & 0.046 \\
\hline Log-probit model & 3 & -424.96 & Yes & 0.078 & 0.062 \\
\hline Hill model & 4 & -423.08 & Yes & 0.090 & 0.069 \\
\hline Proast M4 & 3 & -422.26 & Yes & 0.077 & $0.069^{\mathrm{a}}$ \\
\hline
\end{tabular}

${ }^{\text {a }}$ Based on 500 bootstrap runs.

Table 6b.

DMN: BMD modelling on liver cell tumours in male rats, top dose excluded

\begin{tabular}{|l|l|l|l|l|l|}
\hline Model & npar & loglik & Accepted & $\begin{array}{l}\text { BMD10 (mg/kg } \\
\text { bw/d) }\end{array}$ & $\begin{array}{l}\text { BMDL10 (mg/kg } \\
\text { bw/d) }\end{array}$ \\
\hline Saturated model & 15 & -387.67 & & & \\
\hline One-stage model & 2 & -396.32 & No & & \\
\hline Two-stage model & 3 & -388.85 & Yes & 0.082 & 0.062 \\
\hline Log-logistic model & 3 & -389.59 & Yes & 0.089 & 0.070 \\
\hline Weibull model & 3 & -389.01 & Yes & 0.085 & 0.066 \\
\hline Log-probit model & 3 & -390.13 & Yes & 0.090 & 0.072 \\
\hline Proast M2 & 2 & -389.06 & Yes & 0.088 & $0.081^{\mathrm{a}}$ \\
\hline
\end{tabular}

${ }^{\text {a }}$ Based on 500 bootstrap runs.

\section{A.6. Ethyl carbamate}

\section{A.6.1. Human exposure data}

Human exposure to ethyl carbamate depends largely on the consumption pattern of alcoholic beverages. When excluding alcoholic beverages, human exposure from food was estimated to be $\approx 20 \mathrm{ng} / \mathrm{kg}$ bw/d (Zimmerli and Schlatter, 1991). When including $300 \mathrm{ml}$ wine per day in the diet, the exposure was estimated to 
be $\approx 70 \mathrm{ng} / \mathrm{kg} \mathrm{bw} / \mathrm{d}$ and consumption of $60 \mathrm{ml}$ stone fruit brandies per day resulted in an estimate of $2000 \mathrm{ng} / \mathrm{kg} \mathrm{bw} / \mathrm{d}$. It has to be noted that the levels of ethyl carbamate in alcoholic beverages, especially in brandies, are much lower today so that these estimates do not reflect current exposure.

\title{
A.6.2. Bioassay data
}

Groups of 48 male and 48 female $\mathrm{B} \mathrm{C} 3 \mathrm{~F}_{1}$ mice received $0,10,30$ or $90 \mathrm{mg} / \mathrm{l}$ ethyl carbamate in the drinking water in the presence of $0 \%, 2.5 \%$ or $5 \%$ ethanol for 2 years (US NTP, 2004). These concentrations of ethyl carbamate corresponded to doses of $0,1.2,3.3$ and $10.1 \mathrm{mg} / \mathrm{kg} \mathrm{bw} / \mathrm{d}$ in male mice and 0 , $0.9,2.8$ and $8.2 \mathrm{mg} / \mathrm{kg}$ bw/ $\mathrm{d}$ in female mice (based on combining the published mean doses calculated for weeks $1-13$, weeks $14-52$ and weeks $53-104$ following multiplication by weighting factors $0.125,0.375$ and 0.5 , respectively). The following tumour incidences following exposure to ethyl carbamate alone were observed in male mice given ethyl carbamate only: hepatocellular adenoma or carcinoma $(12 / 46,18 / 47,2 / 46,23 / 44)$, alveolar/bronchiolar adenoma or carcinoma $(5 / 48,18 / 48,29 / 47,37 / 48)$, harderian gland adenoma or carcinoma $(3 / 47,12 / 47,30 / 47,38 / 47)$, heart haemangiosarcoma $(0 / 48,0 / 48,1 / 47,5 / 48)$ and forestomach squamous cell papilloma or carcinoma $(0 / 46,2 / 47,3 / 44,5 / 45)$ and in female mice: liver haemangiosarcoma $(0 / 48,0 / 47,1 / 47,7 / 47)$, hepatocelullar adenoma or carcinoma $(5 / 48,11 / 47,20 / 47,19 / 47)$, alveolar/bronchiolar adenoma or carcinoma $(6 / 48,8 / 48,28 / 48,39 / 47)$, Harderian gland adenoma or carcinoma $(3 / 48,11 / 48,19 / 48,30 / 48)$, mammary gland acanthoma or adenocarcinoma (4/47, 4/46, 4/46, 22/48), ovary gland benign or malignant granulosa cell tumour $(0 / 48,0 / 46,2 / 46,5 / 39)$, uterine haemangiocarcinoma $(0 / 48,0 / 47,0 / 48,2 / 46)$, spleen haemangiosarcoma $(0 / 48$, $0 / 45,1 / 47,4 / 46)$ and skin haemangiosarcoma $(0 / 48,0 / 48,0 / 46,2 / 48)$.

\section{A.6.3. Calculation of T25 values}

\author{
Remarks on study \\ Species, strain, sex Mice, B6C3F1, male \\ Route Oral, drinking water \\ Critical endpoint Alveolar/bronchiolar adenoma or carcinoma \\ Critical dose $\quad 1.2 \mathrm{mg} / \mathrm{kg} \mathrm{bw} / \mathrm{d}$ \\ Duration 104 weeks (default)
}

Lowest dose with a significantly increased tumour incidence

Control

$5 / 48(10.4 \%)$

Dose $1.2 \mathrm{mg} / \mathrm{kg} \mathrm{bw} / \mathrm{d} \quad 18 / 48(37.5 \%)$

Net increase $\quad[(37.5 / 100-10.4 / 100) /(1-10.4 / 100)] \times 100=30.2$

T25 calculation: 


$$
\mathrm{T} 25=25 / 30.2 \times 1.2 \mathrm{mg} / \mathrm{kg} \mathrm{bw} / \mathrm{d}=1.0 \mathrm{mg} / \mathrm{kg} \mathrm{kw} / \mathrm{d}
$$

\section{A.6.4. Calculation of BMDL10 values}

Table 7 shows the BMD calculations as modelled on lung tumours in rats of both sexes. Because there was no significant sex differences in the incidence of alveolar/bronchiolar adenoma or carcinoma, the data for males and females were combined to calculate the BMD (i.e. $0,11 / 96 ; 0.9 \mathrm{mg} / \mathrm{kg} \mathrm{bw} / \mathrm{d}, 8 / 48 ; 1.2 \mathrm{mg} / \mathrm{kg}$ bw/d, 18/48; $2.8 \mathrm{mg} / \mathrm{kg} \mathrm{bw/d}, 28 / 48 ; 3.3 \mathrm{mg} / \mathrm{kg} \mathrm{bw} / \mathrm{d}, 29 / 47 ; 8.2 \mathrm{mg} / \mathrm{kg} \mathrm{bw} / \mathrm{d}$, $39 / 47 ; 10.1 \mathrm{mg} / \mathrm{kg} \mathrm{bw} / \mathrm{d}, 37 / 48)$. The lowest BMDL10 value is $0.28 \mathrm{mg} / \mathrm{kg} \mathrm{bw} / \mathrm{d}$.

Table 7.

Ethyl carbamate: BMD modelling on lung tumours in rats (both sexes)

\begin{tabular}{|l|l|l|l|l|l|}
\hline Model & npar & loglik & Accepted & $\begin{array}{l}\text { BMD10 (mg/kg } \\
\text { bw/d) }\end{array}$ & $\begin{array}{l}\text { BMDL10 (mg/kg } \\
\text { bw/d) }\end{array}$ \\
\hline Saturated model & 8 & -198.67 & & & \\
\hline One-stage model & 2 & -204.03 & Yes & 0.55 & 0.46 \\
\hline Two-stage model & 3 & -204.03 & No & 0.55 & \\
\hline Log-logistic model & 3 & -201.69 & Yes & 0.50 & 0.28 \\
\hline Weibull model & 3 & -204.03 & Yes & 0.55 & 0.46 \\
\hline Log-probit model & 3 & -201.69 & Yes & 0.55 & 0.30 \\
\hline Proast M4 & 3 & -200.55 & Yes & 0.63 & $0.51^{\text {a }}$ \\
\hline
\end{tabular}

${ }^{\text {a }}$ Based on 500 bootstrap runs.

${ }^{\mathrm{b}}$ Fitted with constraint to prevent supralinearity.

\section{A.7. PhIP}

\section{A.7.1. Human exposure data}

Intake estimates for PhIP are scarce. For illustrative purposes, an exposure estimate of $4.8-7.6 \mathrm{ng} / \mathrm{kg}$ bw/d was taken from the US National Toxicology Program Executive Committee Working Group for the Report on Carcinogens (2002) (based on mean intake value of $285.5-457 \mathrm{ng} / \mathrm{d}$ and assuming a mean body weight of $60 \mathrm{~kg}$ ).

\section{A.7.2. Bioassay data}

Groups of 30 male and 30 female Fischer 344 strain rats, were fed PhIP in the diet at levels of $25 \mathrm{ppm}$ corresponding to doses of $0.90 \mathrm{mg} / \mathrm{kg} \mathrm{bw} / \mathrm{d}$ in males and $0.86 \mathrm{mg} / \mathrm{kg} \mathrm{bw} / \mathrm{d}$ in females or $100 \mathrm{ppm}$ corresponding to $3.44 \mathrm{mg} / \mathrm{kg} \mathrm{bw} / \mathrm{d}$ in males and $3.76 \mathrm{mg} / \mathrm{kg} \mathrm{bw} / \mathrm{d}$ in females (Hasegawa et al., 1993). Surviving rats were sacrificed at 104 weeks. The incidences of colon and mammary tumours and leukaemias in the animals were as follows: Male control 0/30 colon tumours, 2/30 mammary tumours ( 2 fibroadenomas) and 3/30 lymphocytic leukemia; male $25 \mathrm{ppm} 0 / 30$ colon tumours, 2/30 mammary tumours ( 2 fibroadenomas) and 6/30 lymphocytic leukemia; male 100 ppm 13/30 colon tumours, 2/30 mammary 
tumours (2 fibroadenomas) and 13/30 lymphocytic leukemia: female control 0/30 colon tumours, $11 / 30$ mammary tumours ( 8 fibroadenoma +3 adenoma) and 2/30 lymphocytic leukemia; female $25 \mathrm{ppm} 0 / 30$ colon tumours, 11/30 mammary tumours ( 5 fibroadenoma +4 adenoma +2 adenocarcinoma) and $3 / 30$ lymphocytic leukemia; female $100 \mathrm{ppm} 4 / 30$ colon tumours, 16/30 mammary tumours ( 1 fibroadenoma +1 adenoma +14 adenocarcinoma) and 5/30 lymphatic leukemia.

\title{
A.7.3. Calculation of T25 values
}

\author{
Remarks on study \\ Species, strain, sex Rat, Fischer 344, male \\ Route Oral, feed \\ Critical endpoint Colon tumours \\ Critical dose $\quad 3.44 \mathrm{mg} / \mathrm{kg} \mathrm{bw} / \mathrm{d}$ \\ Duration 104 weeks (default)
}

Lowest dose with a significantly increased tumour incidence

Control

$0 / 30(0 \%)$

Dose $3.44 \mathrm{mg} / \mathrm{kg} \mathrm{bw} / \mathrm{d}$

$13 / 30(43.3 \%)$

Net increase

$43.3 \%$

T25 calculation:

$$
\mathrm{T} 25=25 / 43.3 \times 3.44 \mathrm{mg} / \mathrm{kg} \mathrm{bw} / \mathrm{d}=2.0 \mathrm{ng} / \mathrm{kg} \mathrm{bw} / \mathrm{d}
$$

\section{A.7.4. Calculation of BMDL10 values}

Table 8 shows the BMD calculations as modelled on colon tumours in male rats. In this endpoint only one dose shows a response, hampering the estimation of a dose-response relationship (see Fig. 3). Nonetheless, the BMDLs for the different models do not differ greatly. The lowest BMDL10 value is $1.25 \mathrm{mg} / \mathrm{kg} \mathrm{bw} / \mathrm{d}$.

Table 8.

PhIP: BMD modelling of colon tumours in males rats

\begin{tabular}{|l|l|l|l|l|l|}
\hline Model & npar & loglik & Accepted & $\begin{array}{l}\text { BMD10 (mg/kg } \\
\text { bw/d) }\end{array}$ & $\begin{array}{l}\text { BMDL10 (mg/kg } \\
\text { bw/d) }\end{array}$ \\
\hline Saturated model & 3 & -20.53 & & & \\
\hline
\end{tabular}




\begin{tabular}{|l|l|l|l|l|l|}
\hline Model & npar & loglik & Accepted & $\begin{array}{l}\text { BMD10 (mg/kg } \\
\text { bw/d) }\end{array}$ & $\begin{array}{l}\text { BMDL10 (mg/kg } \\
\text { bw/d) }\end{array}$ \\
\hline One-stage model & 2 & -24.35 & No & & \\
\hline Two-stage model & 3 & -21.64 & Yes & 1.55 & 1.25 \\
\hline Log-logistic model & 3 & -20.53 & Yes & 3.01 & 1.36 \\
\hline Weibull model & 3 & -20.53 & Yes & 3.05 & 1.40 \\
\hline Log-probit model & 3 & -20.53 & Yes & 2.57 & 1.29 \\
\hline Proast M2 & 2 & -20.53 & Yes & 2.99 & $2.88^{\mathrm{a}}$ \\
\hline
\end{tabular}

${ }^{a}$ Based on 500 bootstrap runs.

proast M2
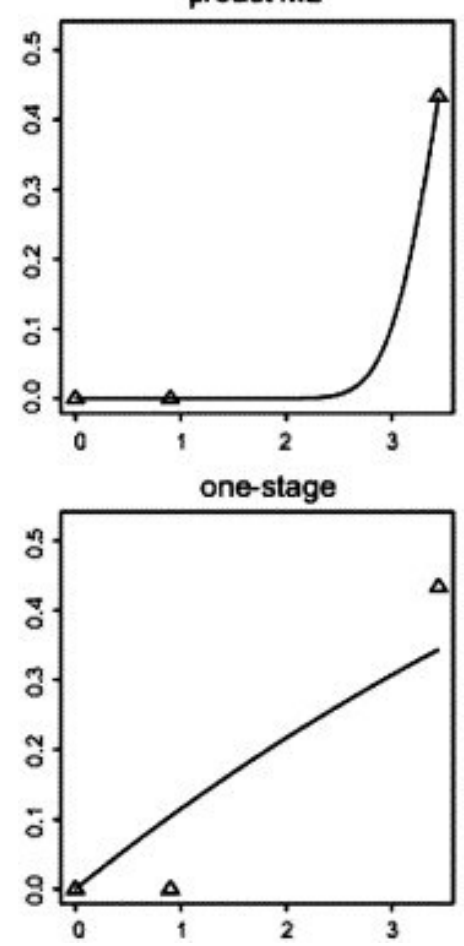

two-stage
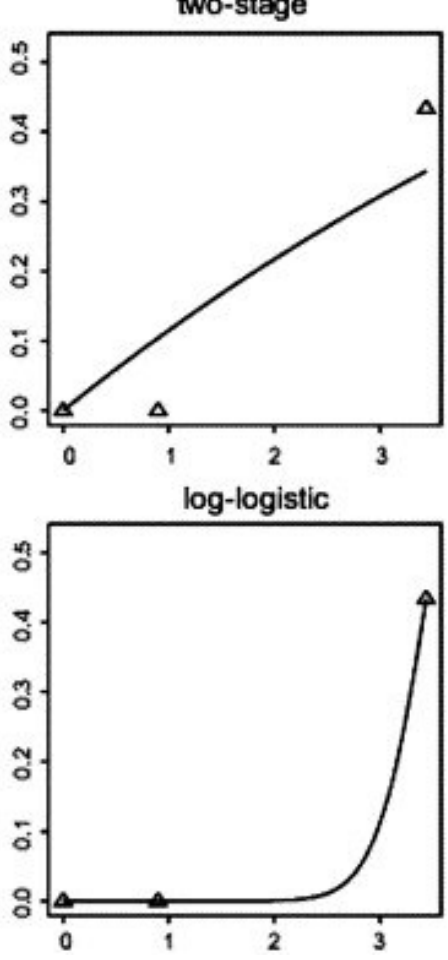

Weibull
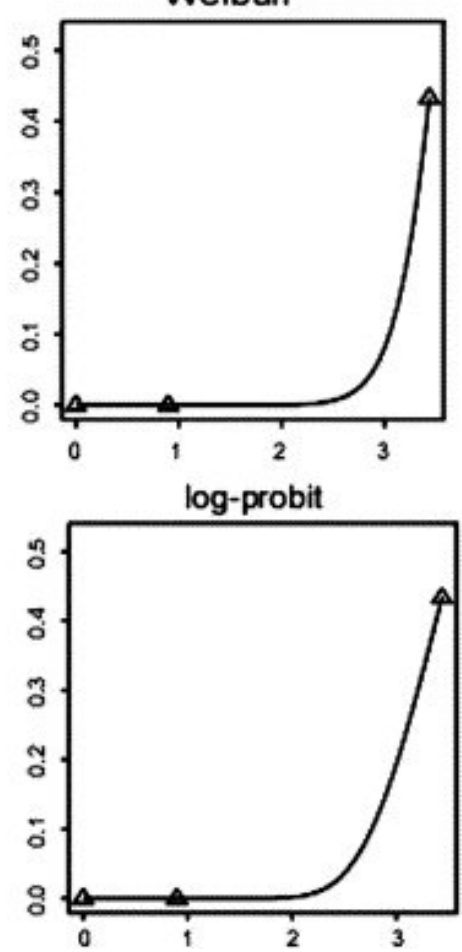

Fig. 3. Different models fitted to colon tumours as a function of PhIP dose.

国 Corresponding author. Tel.: +32 2771 0014; fax: +32 27620044 .

${ }^{1}$ Current address: UCB Celltech, 208 Bath Road, Slough SL1 3WE, Berks, United Kingdom.

${ }^{2}$ Response to a request from the European Commission for an SCF opinion on the scientific basis of the concept of threshold of regulation in relation to food contact materials.

${ }^{3}$ Sound data on the mode of action of a compound as well as its kinetics in a given species are a prerequisite for any risk assessment as otherwise the relevance of animal tumor data for human risk assessment is unclear.

${ }^{4}$ The lowest tumour incidence that can be assessed depends on the background tumour incidence and on the number of animals used: to establish a $10 \%$ increase in tumour rate with a confidence limit of $95 \%$ in a population with a spontaneous rate of $1 \%, 40$ animals are necessary. To assess an increase 
Food and Chemical Toxicology Volume 44, Issue 10 , October 2006, Pages 1613-1635

by $1 \%$ or $0.1 \%, 1100$ or 80,000 animals per dose group, respectively, would be necessary. 5 The human exposure data used should be considered as examples as no thorough exposure assessments with updated occurrence data and food consumption were made for the selected carcinogens. Whenever possible, national data for different parts of the population should be used to calculate actual human exposure. 